\title{
Does Anticipated Information Impose a Cost on Risk-Averse Investors? A Test of the Hirshleifer Effect
}

\author{
RYAN T. BALL $\mathbf{L}^{*}$
}

Received 6 July 2011; accepted 30 October 2012

\begin{abstract}
This paper theoretically and empirically investigates how the risk of future adverse price changes created by the anticipated arrival of information influences risk-averse investors' trading decisions in institutionally imperfect capital markets. Specifically, I examine how the selling activity of individual investors immediately following an earnings announcement is influenced by the tradeoff between risk-sharing benefits of immediate trade and explicit transaction costs imposed on such trades. Consistent with my theoretically derived predictions, I find that investors' current trading decisions are less sensitive to the incremental transaction costs created by short-term capital
\end{abstract}

\footnotetext{
${ }^{*}$ Ross School of Business, The University of Michigan.

Accepted by Haresh Sapra. This paper is based on my doctoral dissertation at the University of North Carolina at Chapel Hill. I thank my advisers Eric Ghysels, Wayne Landsman, Mark Lang, Doug Shackelford, and especially Robert Bushman and Ro Verrecchia for their continuous support and guidance on this project. This paper benefited from comments by an anonymous referee, Phil Berger, Hans Christensen, Thomas Hemmer, Terry Shevlin, and seminar participants at the University of Chicago, Columbia University, Harvard, London Business School, the University of Minnesota Empirical Conference, MIT, the University of North Carolina at Chapel Hill, Northwestern University, Purdue University, Stanford University, Tel Aviv University, the University of Texas at Austin, Wharton, and the AFAANZ Doctoral Colloquium in Melbourne, Australia. Financial support from the University of Michigan Ross School of Business, the University of Chicago Booth School of Business and the Neubaurer Family Faculty Fellowship are gratefully acknowledged.
} 
gains taxes on trading profits, as both the duration and intensity of the risk of future adverse price changes increase. This evidence is consistent with an incremental cost to investors that results from the revelation of precise information, which is commonly referred to as the Hirshleifer Effect.

\section{Introduction}

In efficient capital markets, stock prices adjust to reflect the arrival of new information, which leads to stock price volatility (e.g., Fama [1970, 1991]). Expected price volatility deriving from the anticipated arrival of new information imposes an incremental welfare cost upon undiversified, risk-averse investors by virtue of their exposure to the risk of adverse price changes (Hirshleifer [1971], Verrecchia [1982] $).{ }^{1}$ In response, risk-averse investors generally desire to trade shares prior to the arrival of information in order to spread the economy's aggregate risk while diversifying their idiosyncratic risks. $^{2}$

In an idealized capital market with frictionless trading, investors can quickly and efficiently balance their portfolios to insure themselves against adverse price changes in the future. However, the existence of costly trading frictions can constrain investors from trading to their desired portfolios, leaving them exposed to incremental welfare costs associated with the risk of adverse price changes from the arrival of new information. This adverse welfare effect of the anticipated arrival of information is commonly referred to as the Hirshleifer Effect (Hirshleifer [1971]).

In this paper, I identify a novel and powerful capital market setting in which to test whether the Hirshleifer Effect can be detected empirically and examine what dimensions of risk are most important to investors. Specifically, I examine the relation between trading volume (a theoretically motivated surrogate for investor welfare) and the risk of adverse price changes in the presence of trading frictions created by the existence of intertemporal tax discontinuities (hereafter ITDs). An ITD results from the incremental capital gains tax rate applied to trading profits on shares held for less than a requisite amount of time. ${ }^{3}$ In order to qualify for the lower longterm capital gains tax, investors are required to hold assets for a requisite amount of time (typically 12 months) before selling them or else incur the

\footnotetext{
${ }^{1}$ Ceteris paribus, anticipated price volatility increases with the precision of the anticipated information.

${ }^{2}$ A prominent theoretical model of optimal risk-sharing in financial markets is the capital asset pricing model (CAPM) of Sharpe [1964] and Lintner [1965]. In the CAPM, risk-averse investors seek to minimize their exposure to the risk of adverse price changes by holding a diversified portfolio consistent with their individual preferences for risk.

${ }^{3}$ Shackelford and Verrecchia [2002] coined the term intertemporal tax discontinuity, which they define as "a circumstance in which different tax rates are applied to gains realized at one point in time versus some other point in time" (p. 205). In the context of my study, an ITD specifically refers to the difference in tax rates applied to long-term versus short-term capital gains.
} 
higher short-term capital gains tax on trading profits. Given an ITD, riskaverse investors face an economic tension between trading immediately to an optimal risk-sharing portfolio at the cost of incurring an incremental tax on realized trading profits, versus postponing trade to avoid the incremental tax while facing the risk of interim adverse price changes. This tension embodies the Hirshleifer Effect and is the focus of this paper.

Guided by a two-period extension of the model proposed by Shackelford and Verrecchia [2002], I empirically document that as price volatility increases, traders become more willing to incur the ITD cost involved with trading before satisfying the requisite ITD holding period in order to trade closer to their optimal risk-sharing portfolio and insulate themselves against anticipated price volatility. In essence, higher anticipated price volatility results in the incremental welfare cost of the anticipated arrival of information dominating transaction costs associated with the ITD, which makes investors more willing to pay the explicit ITD transaction cost to shed this risk. An increase in the precision of anticipated information reduces the sensitivity of investors' trading decisions to ITD costs.

More specifically, I find that in weighing ITD costs against the risk of adverse price movements, investors consider both the intensity and the $d u$ ration of the risk of adverse price changes. Intuitively, intensity captures the risk of adverse price movements per unit of time, while duration captures the amount of time that such risk must be held. For example, a trader may have only a few days left in the requisite ITD holding period, but the risk of adverse price movement is very intense during the short remaining interval, creating incentives for the investor to trade now toward an optimal portfolio to avoid adverse price movements. Likewise, even if intensity is low, an investor with a significant amount of time before qualifying for the favorable long-term tax rate can still have strong incentives to trade today because the low-intensity risk must be held over a long time period.

First, I empirically examine the impact of the duration component of risk on the association between trading activity and ITD costs following a quarterly earnings announcement. At a given point in time, investors in a firm's shares have purchased their shares at different times in the past, which means they face a different duration of risk as well as a different ITD cost because of the different prices paid for the shares. I exploit this variation in the ITD and duration of risk tradeoff for a given firm's investors at a given point in time (e.g., following a quarterly earnings announcement) by including separate ITD costs for each holding period relative to qualification for the lower tax rate as separate explanatory variables in a regression explaining trading activity. This makes it possible to test whether the sensitivity of trading activity to ITD costs decreases as the number of days remaining until qualification increases (i.e., duration of risk increases). Consistent with the Hirshleifer Effect, I find evidence that investors' trading decisions become less sensitive to ITD costs as the duration of the risk they face increases. Specifically, the results indicate that an increase in the duration of risk from one day to one year completely eliminates any ITD incentive to postpone 
trade because it imposes too high of an implicit cost on risk-averse investors, which highlights the important economic costs associated with anticipated information.

Second, using the average daily stock return volatility as a proxy for the intensity of risk, I find evidence that the sensitivity of trading activity to ITD costs decreases as the risk of adverse price changes per unit of time increases (i.e., intensity increases). In other words, the higher the anticipated price volatility, the less influential ITD incentives are on current trading decisions as investors become more willing to trade now to hedge the more intense risk, despite incurring higher tax costs. However, while the results are statistically significant, the economic magnitude is less pronounced compared to the duration of risk results discussed previously. Moving from the lowest to highest intensity of risk reduces the sensitivity of investors' trading decisions to ITD costs by $25.7 \%$. This implies that for every $\$ 100$ a risk-averse investor postpones trading in a stock with low intensity of risk in order to avoid paying any ITD taxes, they are willing to pay $\$ 5.04$ in additional taxes on immediate trade for a stock with high intensity of risk when the difference between the long-term and short-term tax rates is $19.6 \%$. Thus, varying the intensity of risk from one extreme to the other does have a substantial economic impact on the sensitivity of trade to ITD costs, but reflects only one fourth of the economic impact of the duration of risk.

Overall, these results contribute to our understanding of economic costs associated with precise information when capital market frictions are present. This stands in sharp contrast to the conventional wisdom that increasing the precision of information leads to an increase in investor welfare (e.g., a lower cost of capital). For example, Neel Foster, a former member of the Financial Accounting Standards Board, states that "More information always equates to less uncertainty, and ... people pay more for uncertainty. In the context of financial information, the end result is that better disclosure results in a lower cost of capital" (Foster [2003]). My study illustrates that investor welfare is decreasing in the precision of anticipated information when capital market frictions are present. In addition, I document that this implicit welfare cost on investors will manifest through trading volume, but not stock price, which implies that the cost of capital may be an incomplete measure of the net effect of information precision on investor welfare (Gao [2010]).

A number of institutional constraints exist that may inhibit investors' ability to optimally make trades, including incomplete capital markets (Merton [1987]), short sale constraints and prohibitions (Diamond and Verrecchia [1987]), bid-ask spreads (Constantinides [1986]), and taxes (Shackelford and Verrecchia [2002]). While each of these transaction costs is potentially important, I choose to examine the trading friction created by the incremental ITD because it offers several important advantages in examining the Hirshleifer Effect relative to other commonly studied transaction costs.

First, and most importantly, an ITD is a perfectly anticipated, timevarying transaction cost with a finite amount of time until expiration. In 
order to qualify for the lower long-term capital gains tax rate, investors are required to hold assets for a requisite amount of time. ${ }^{4}$ This is crucial for empirical tests of the Hirshleifer Effect because it makes it possible to measure the specific time horizon over which investors assess the risk of adverse price changes in determining the optimal tradeoff between risk and ITD costs. In contrast, most other transaction costs, such as bid-ask spreads and long-term capital gains taxes, do not have an anticipated time variation that allows investors to optimally avoid them. ${ }^{5}$ For example, investors can avoid paying long-term capital gains taxes by postponing the sale of their portfolio until death. However, investors' expectations over their life expectancy are unobservable.

Second, an ITD represents a potentially significant trading cost to investors. Currently, the maximum ITD cost imposed on investors, equal to the difference in the maximum statutory capital gains tax rates applied to short-term and long-term gains, is $20 \%$ but has historically been as low as $0 \%$ (1988-1990) and as high as 30\% (1982-1986). Finally, a large body of empirical evidence supports an important role for ITD costs in shaping investor demand and trading volume. For example, Blouin, Raedy, and Shackelford [2003] find a negative and statistically significant association between ITD costs and trading volume following quarterly earnings announcements. Reese [1998] finds similar evidence using a sample of IPO firms. The collective evidence in the literature provides a strong foundation for empirically exploiting the tension created by ITD costs to powerfully isolate and test the Hirshlefer Effect.

This study contributes to a large body of literature, dating back at least to Hirshleifer [1971], that theoretically examines the welfare implications of anticipated information. Hirshleifer [1971] demonstrates that, in a pure exchange economy, risk-averse investors are incrementally worse off (in expectation) if they are not allowed to contract (or trade) prior to the release of anticipated information. Verrecchia [2001] refers to this as the adverse risk-sharing effect of increased disclosure. ${ }^{6}$ While a large number of theory papers have debated the merits of the Hirshleifer Effect, there is a lack of empirical evidence to support its validity. Two exceptions include Quaid and Morris [1993] and Lerman et al. [1996], which provide evidence of the Hirshleifer Effect within a small sample medical setting. Specifically, these studies find that subjects reject costless information related to free

\footnotetext{
${ }^{4}$ Historically, the requisite holding period has been $6,9,12$, and 18 months. The ITD holding period of 12 months is the most common.

${ }^{5}$ While the magnitude of bid-ask spreads and long-term capital gain tax rates can change over time, the change is not fully anticipated (except in unusual circumstances) and thus does not provide investors with an incentive known in advance of the event.

${ }^{6}$ Subsequent studies formalize Hirshleifer's argument (e.g., Marshall [1974], Hakansson, Kunkel, and Ohlson [1982]) and develop theoretical models that examine the welfare role of anticipated information using alternative assumptions and settings. See Verrecchia [1982], Diamond [1985], Bushman [1991], Alles and Lundholm [1993], and Campbell [2004], among others. Verrecchia (2001; section 4) provides an extensive review of this literature.
} 
screening for hereditary diseases because of a fear of losing an opportunity to insure against the disease. In short, the empirical findings in these studies support the Hirshleifer Effect, but are difficult to generalize to a large capital market setting.

It is not clear that investors in my setting are sufficiently risk-averse or sensitive to ITD transaction costs to create the Hirshleifer Effect at an economically meaningful magnitude. For example, portfolio diversification may eliminate some of the risk of adverse price changes or investors may have a sufficiently high tolerance for risk to reduce the welfare implications associated with risk-sharing. In addition, the ITD transaction cost investors actually consider may be substantially less than the maximum statutory amounts for a number of reasons. First, some investors may have held shares for the requisite amount of time and qualified for the lower long-term capital gain tax rate. These investors have no ITD incentive to postpone trading. Second, a portion of any short-term capital gains accrued in one security may be partially offset by short-term capital losses from another security in an investor's portfolio, leading to a lower ITD incentive to postpone trades. Third, some investors, such as institutions, may be tax-exempt. ${ }^{7}$ The extent to which these countervailing forces are present works against finding any evidence of the Hirshleifer Effect. Despite these mitigating factors, the results presented in this paper are consistent with the notion that anticipated information directly influences investors' trading behavior in a manner consistent with the Hirshleifer Effect when ITD transaction costs are present.

The rest of the paper is organized as follows: section 2 outlines the conceptual framework and empirical predication, section 3 describes the empirical sample and variable definitions, section 4 presents the empirical analysis and results, and section 5 concludes.

\section{Conceptual Framework}

My conceptualization of the impact of anticipated information on investor welfare and trading behavior builds on Shackelford and Verrecchia's (2002) model of market responses in the presence of an ITD. In their model, risk-averse investors, chararacterd by a risk tolerance parameter, $\gamma$, are endowed with suboptimal risk-sharing portfolios and reduce their trading activity as part of an optimal strategy to avoid paying a capital gain tax $(\tau)$ on trades prior to realizing a liquidating dividend. The key insight from their model is that an increase in ITD transaction cost imposed on selling shareholders leads to a reduction in the supply of shares available for purchase and, therefore, an increase in the equilibrium price and a decrease in trading volume.

\footnotetext{
${ }^{7}$ See Shackelford and Shevlin [2001] and Blouin, Raedy, and Shackelford [2003] for a comprehensive review of why capital gains taxes may not matter to investors.
} 


\subsection{SHACKELFORD AND VERRECCHIA (2002) —EXTENSION}

In this section, I extend the Shackelford and Verrecchia (SV) model to allow risk-averse investors a second round of trade prior to the realization of the liquidating dividend when the tax rate is equal to zero. ${ }^{8}$ Thus, investors can optimally avoid paying the capital gain tax in the first period by postponing their trade until the second period. However, investors anticipate they will observe a public signal, $\tilde{y}=\tilde{u}+\tilde{\varepsilon}$, between periods 1 and 2 . The noise in the signal, $\tilde{\varepsilon}$, is independently and normally distributed with a mean of 0 and a precision (inverse of variance) of $s$. The information contained in this signal creates an incentive for risk-averse investors to trade in the first round to protect themselves from adverse price changes in the second round despite having to pay a higher tax rate on their immediate trades. Under these conditions, the equilibrium price $\left(P_{1}\right)$ and trading volume $\left(V_{1}\right)$ in the initial round of trade becomes:

$$
\begin{gathered}
P_{1}=\frac{\bar{u}-\frac{x}{\gamma}-\theta \tau P_{0}}{(1-\theta \tau)}, \\
V_{1}=V^{*}-\gamma \theta(1-\theta) \frac{\tau \Delta P_{1}}{\operatorname{Var}\left[\tilde{P}_{2}\right]} \geq 0,
\end{gathered}
$$

where $V^{*}$ is the optimal risk-sharing trading volume, $\operatorname{Var}\left[\tilde{P}_{2}\right]=\left(1+s^{-1}\right)^{-1}$ is the variance of price in the second round of trading, $\Delta P_{1}$ is the amount of capital gain in the first round of trading, $\bar{u}$ is the expected payoff of the risky asset, $x$ is the supply of the risky asset, and $\theta$ is the proportion of selling investors in the economy.

Both expressions highlight the interaction between the ITD transaction cost and anticipated information in forming the equilibrium price and trading volume. First, the ITD transaction cost imposed on selling shareholders in the first round of trade leads them to adjust their demand, which changes the supply of shares available for purchase. Thus, an increase in the ITD transaction cost reduces the supply of shares, which leads to an increase in the equilibrium price and a decrease in the trading volume. This effect is identical to the equilibrium behavior in Proposition 1 of SV. ${ }^{9}$

Second, the risk of adverse price changes creates an incentive to trade immediately so that investors can insure themselves against adverse price changes. Thus, an increase in the precision of the intermediate signal leads to an increase in anticipated price volatility, which leads to a reduction in the sensitivity of trading volume to the ITD cost. In other words, as anticipated information becomes more precise, investors are more willing to

\footnotetext{
${ }^{8}$ Given the development of the basic rational expectations model is relatively well developed in SV, I focus primarily on my extension of their model. Complete details of my model are provided in the appendix.

${ }^{9}$ The situation where selling shareholders demand compensation from buying shareholders for the capital gains taxes paid on trades is commonly referred to as the "lock-in" effect (e.g., Landsman and Shackelford [1995], Klein [1999], Jin [2006], Dai et al. [2008]).
} 
incur the explicit tax cost of immediate trade in order to shed the implicit welfare cost associated with the risk of holding the shares until the next round of trade.

Given the wedge created by the ITD, both sellers and buyers are exposed to the anticipated information, which causes them to simultaneously increase their demand and supply of shares in order to shed their risk. The increase in demand by buying shareholders leads to a price increase and is simultaneously offset by the increase in supply by selling shareholders. Thus, the equilibrium price does not depend on the precision of the anticipated information. In contrast, anticipated information does affect equilibrium trading volume as both buying and selling shareholders increase their supply and demand, respectively, which increases trading volume. Investors will trade more shares, despite having to pay the ITD transaction cost, as the precision of anticipated information increases. In other words, investors are willing to pay the explicit transaction cost in order to reduce the implicit utility cost imposed by exposure to adverse price changes stemming from the anticipated arrival of new information.

At one extreme, when the anticipated signals provide no additional information (i.e., $s \rightarrow 0$ ), investors know exactly what the price in the second round of trading will be because they know there will be no new information to update their beliefs about the underlying value of the risky asset. Consequently, investors will not trade in the first period because they can avoid paying the ITD without any risk of adverse price changes in the second period.

At the other extreme, when the anticipated signals are expected to fully reveal the payoff of the risky asset (i.e., $s \rightarrow \infty$ ), investors trade as close as possible to the optimal risk-sharing allocation despite having to pay the ITD transaction cost. ${ }^{10}$

\subsection{EXPECTED UTILITY AND THE HIRSHLEIFER EFFECT}

The results of the previous section demonstrate that the existence of an ITD transaction cost creates an incentive to not trade to an optimal risksharing portfolio, which leaves investors exposed to the risk associated with anticipated information. This exposure implies that individual investor welfare, defined as expected utility $(\bar{U})$ in the first round of trade, is weakly decreasing in the precision, $s$, of the anticipated signal when an ITD transaction cost, $\tau$, is present (i.e., the Hirshleifer Effect). In the absence of an ITD (i.e., $\tau=0$ ), each investor's expected utility is not affected by the precision of the anticipated signal, $s$. However, in the presence of an ITD transaction cost (i.e., $\tau>0$ ), their expected utility is decreasing in the precision of the

\footnotetext{
${ }^{10}$ By allowing $s$ to go to $\infty$, my model effectively collapses to the one-period model of Shackelford and Verrecchia [2002]. Thus, the SV model may be viewed as an extreme case of my model, which leaves no scope for varying the role of anticipated information, which is the focus of my paper.
} 
anticipated signal, $s$. That is,

$$
\left.\frac{\partial \bar{U}_{i}}{\partial s}\right|_{\tau=0}=0,\left.\quad \frac{\partial \bar{U}_{i}}{\partial s}\right|_{\tau>0}<0, \quad \text { and } \quad \frac{\partial}{\partial \tau}\left(\frac{\partial \bar{U}_{i}}{\partial s}\right)<0 .
$$

This result, which is derived in the appendix, illustrates the Hirshleifer Effect. In the absence of an ITD transaction cost, investors are not constrained from trading in the first period and, therefore, immediately trade to the optimal risk-sharing portfolio prior to the release of the anticipated signal prior to the second round of trade. Thus, the investors optimally insulate themselves from risk of adverse price changes in the second period, which makes them insensitive to the precision of the anticipated information signal. In contrast, the presence of an ITD in the first period drives a wedge between the equilibrium and an optimal risk-sharing allocation, which exposes investors to the risk of adverse price changes stemming from the anticipated arrival of new information in the second round of trade. An increase in the ITD cost creates a larger wedge, which, in turn, leads to a larger scope for anticipated information and increases the sensitivity of investors' expected utility to the precision of the anticipated information.

This is consistent with the pure exchange model in Hirshleifer [1971] in which investors are not allowed to trade prior to the release of the anticipated public signal. A key difference in my model is that investors are not forbidden from trading prior to the signal, but instead are given a real monetary incentive to postpone trading in order to avoid paying the ITD transaction cost. This feature of the model facilitates an empirical test of the Hirshleifer Effect by examining how variation in the precision of anticipated information changes the sensitivity of investors' trading decisions to ITD transaction costs.

\subsection{EMPIRICAL PREDICTIONS}

The investor welfare results in the previous section cannot be directly tested because investors' expected utility is not observable. As discussed above, the interaction between ITD costs and the precision of anticipated information is expected to affect trading volume, but not stock price. Therefore, in this section I develop empirical predictions related to trading volume to test for evidence consistent with the Hirshleifer Effect.

Equation (2) illustrates the key economic tension of the paper. Actual trading volume is less than optimal risk-sharing volume by an amount proportional to the ratio of the aggregate ITD cost to the risk of an adverse price change in the second round of trade. Specifically, as the ITD cost of trading increases, investors trade less to avoid paying the explicit transaction cost. That is, trading is (weakly) decreasing in the ITD incentive among investors and results in a negative association between trading volume and the ITD cost. This is the main result derived in the SV model and empirically supported by subsequent studies (e.g., Blouin, Raedy, and Shackelford [2003]). The key insight from my study is that investors also consider the implicit welfare cost from the risk of adverse price changes stemming from 
the anticipated arrival of new information in subsequent periods. Therefore, the negative relation between trading volume and the ITD incentive among investors is (weakly) increasing (i.e., becoming less negative) in the precision of the anticipated information, $s$. This occurs because investors' trading decisions become less sensitive to the ITD transaction cost with increases in the cost of anticipated information, captured by the variance of future price. Investors are willing to pay the higher explicit ITD transaction cost to reduce the implicit welfare cost created by anticipated information and the risk of future adverse price movements. In other words, anticipated information imposes a cost on investors (i.e., the Hirshleifer Effect), which is reflected in the comparative statics presented in the previous section.

The precision of the anticipated signal and, therefore, the total risk faced by investors can be decomposed into a duration component and an intensity component. Intuitively, duration captures the amount of time that the risk must be held until qualification for the lower rate, while intensity captures the risk of adverse price movement per unit of time. Both effects lead to the two main empirical predictions. The first empirical implication relates the duration component of risk and is stated as follows:

Empirical Implication 1 The negative impact of ITD costs on trading activity following an earnings announcement is mitigated (i.e., is less negative) as the time to qualification increases (i.e., the duration of risk increases).

As the time to qualification increases, an investor must remain exposed to the risk of adverse price movements over a longer period. Therefore, investors optimally trade more shares today to reduce risk, despite the negative wealth effect of paying the higher short-term tax rate on trading profits. The second empirical implication relates the intensity component of risk and is stated as follows:

Empirical Implication 2 The negative impact of ITD costs on trading activity following an earnings announcement is mitigated (i.e., less negative) as the intensity of risk per unit of time increases.

As the intensity of risk per unit of time increases, investors are more willing to trade early, despite the higher taxes, to insulate themselves against the higher implicit welfare costs associated with the risk of adverse price changes.

\section{Empirical Sample and Variable Definitions}

\subsection{SAMPLE SELECTION}

To test my empirical predictions, I examine trading activity around quarterly earnings announcements. While quarterly earnings announcements are not an inherent aspect of the conceptual framework, such a setting provides two benefits. First, quarterly earnings announcements provide a large sample setting associated with trading activity (e.g., Beaver [1968], Morse [1981], Bamber [1986], Landsman and Maydew [2002]). As a result, 
quarterly earnings announcements are likely to satisfy the theoretical criterion of "given that investors desire to trade" and thus provide a relatively powerful setting to detect whether risk and ITD incentives interact to influence trading volume in a manner consistent with the Hirshleifer Effect. ${ }^{11}$

Second, a necessary condition for the existence of a relation between risk and trading activity is that ITD incentives have to influence investors' trading decisions. ${ }^{12}$ Consistent with this necessary condition, Blouin, Raedy, and Shackelford [2003] and Hurtt and Seida [2004] document evidence of a negative and significant association between ITDs and trading volume around quarterly earnings announcements. This supporting evidence provides prima facie motivation for examining the role of risk in mitigating the sensitivity of trading to ITD transaction costs around quarterly earnings announcements.

I begin by collecting data on all NYSE-listed firms with an available quarterly earnings announcement date between 1982 and 2002, as found in Compustat. Next, I eliminate observations with a quarterly earnings announcement falling on a date when the requisite ITD holding period is not equal to 12 months. ${ }^{13}$ Finally, I require that each observation has the necessary data from Compustat, CRSP, I/B/E/S, Thomson Financial, TAQ, and ISSM to compute all variables used in the empirical analysis. The final sample contains 35,222 quarterly earnings announcement observations.

\subsection{VARIABLE DEFINITIONS}

The empirical implications developed in section 2 rely upon three important measures: (1) trading volume (the outcome or dependent variable), (2) the ITD incentive to postpone trading, and (3) the risk incentive to trade immediately. In this section, I describe the empirical proxies for each of the three key measures as well as other control variables used in the empirical analysis.

First, the dependent variable employed in multivariate tests is the cumulative three-day abnormal selling activity by individual investors, $A V O L$, around quarterly earnings announcements. Using intra-day trading data

\footnotetext{
${ }^{11}$ If ITD transaction costs matter to investors, then they should affect trading volume on all trading days throughout the year. Therefore, any impact of ITD transaction costs on trading activity around quarterly earnings announcement dates may be understated relative to the actual effect as a result of the distortion in trading volume from the ongoing, unobservable influences of ITD transaction costs prior to the earnings disclosure. This biases against finding any results consistent with the model's predictions.

${ }^{12}$ Absent an ITD transaction cost, investors will immediately trade to their optimal risksharing portfolio to insulate themselves from future adverse price changes. In other words, investors will trade to the same portfolio regardless of the risk of future adverse price changes, implying that there is no relation between trading volume and risk. Thus, a necessary condition for such a relationship is the existence of a source of market friction, such as an ITD.

13 This filter excludes announcements made from June 23, 1985 through July 1, 1988 (sixmonth holding period) and between July 29, 1997 and December 31, 1997 (18-month holding period).
} 
from the ISSM and TAQ databases and following Lee and Radhakrishna [2000], I classify trades of less than $\$ 10,000$ (in 1990-dollars) as made by individual investors and determine the trade direction from the Lee and Ready [1991] algorithm. Examining the selling activity of small trades in this manner increases the likelihood of capturing selling activity by more tax-sensitive individual investors. ${ }^{14}$

I compute a daily selling measure, $S_{t}$, for individual investors equal to the natural logarithm of one plus the number of trades classified as sell orders by individual investors. Following Hurtt and Seida [2004], expected daily selling activity by individual investors for a given firm during each day of an earnings release period, days $t-1$ to $t+1$, is the average of the daily individual selling metric, $S_{t}$, for that firm during the 50 days immediately preceding day $t-1$, after excluding prior three-day earnings announcement windows. AVOL is then computed as the mean selling activity by individual investors, $S_{t}$, less the expected daily selling activity over the three-day earnings announcement period scaled by the standard deviation of $S_{t}$ over the 50-day estimation period. ${ }^{15}$

Second, I construct an empirical proxy for the total ITD incentive, ITD, aggregated across all investors at the earnings announcement. Individual investor's ITD incentive to postpone trading is the product of the difference between the short-term and long-term capital gains tax rates, $\triangle R A T E$, and the change in stock price, $\Delta P_{n}$, from the time the shares were acquired to the date of the earnings announcement. Consistent with prior ITD studies, I define $\triangle R A T E$ as the maximum statutory short-term capital gains tax rate less the maximum statutory long-term capital gains tax rate at the earnings announcement date.

The change in stock price at the announcement date, $\Delta P_{n}$, is defined as the logarithm of the closing stock price on day $t-2, \ln \left(P_{t-2}\right)$, minus the logarithm of the initial purchase price (adjusted for stock splits and stock dividends) on day $t-n, \ln \left(P_{t-n}\right)$, where $n$ is the number of trading days prior to the earnings announcement on which the asset was purchased. Trading activity should reflect the aggregate ITD incentive and, therefore, the aggregate price change among all investors on day $t$. Before aggregating price changes, it is important to note that a change in price with respect to a given day in the past may not induce a strong ITD effect on abnormal trading activity around the earnings announcement if relatively few shares were traded on that particular day. In other words, if very few shares were transacted on day $t-n$, then there is a low probability that an investor trading at the earnings announcement date purchased shares on $t-n$. The price change computed for this day should receive a lower weight than a

\footnotetext{
${ }^{14}$ Results are quantitatively similar if cutoff values of less than $\$ 5,000$ or $\$ 20,000$ are used to proxy for trades made by individual investors.

${ }^{15}$ In an untabulated analysis, I construct an alternative measure of abnormal trading volume around the earnings announcement using the "market" model of Ajinkya and Jain [1989]. All inferences reported in the paper are similar using this alternative specification.
} 
trading day with high volume when constructing an aggregate price change measure. ${ }^{16}$ Therefore, I compute a volume-weighted average price change $\bar{\Delta} P$ over the 248 trading days (i.e., within the requisite ITD holding period, $n \in[3,4, \ldots, 250])$ immediately preceding $t-1$ as follows:

$$
\bar{\Delta} P=\sum_{n=3}^{250} \Delta P_{n}=\frac{1}{248} \sum_{n=3}^{250} w_{n} \cdot\left[\ln \left(P_{t-2}\right)-\ln \left(P_{t-n}\right)\right],
$$

where $\Delta P_{n}$ is the daily volume-weighted change in price from $t-n$ to $t-$ 2 and $w_{n}$ is equal to the daily volume on day $t-n$ divided by the firm's cumulative trading volume over the two years immediately preceding the earnings announcement. Weighting price changes with respect to the twoyear trading volume implies that the sum of the daily weights applied to days $t-250$ to $t-3$ will be less than one. This is intended to capture the fraction of traders that may have already held shares for more than one year and are no longer subject to an ITD. ${ }^{17}$ The aggregate ITD incentive to postpone trading, ITD, is estimated as the product of $\triangle R A T E$ and $\bar{\Delta} P$.

Third, I consider empirical proxies for the total amount of risk each investor considers. The total risk is an increasing function of both the intensity and the duration of the anticipated price volatility. The duration component represents the amount of time over which a given risk intensity must be held. It is defined as the number of trading days an investor who purchased shares on day $t-n$ has remaining until qualification for the lower tax rate. Specifically, duration, $d$, is equal to $250-n$ and is expressed in number of trading days. ${ }^{18}$ Consequently, within a single observation, $d$ will vary among investors depending on the number of trading days, $n$, prior to the announcement date that each investor purchased shares. The intensity component represents the risk of adverse price changes per unit of time (e.g., per trading day). I define INTENSITY as the variance of firm-specific daily stock returns in excess of the

\footnotetext{
${ }^{16}$ The volume traded on a past date will not necessarily be held up to or traded on the earnings announcement date. This makes past daily volumes a noisy proxy for the cross-section of investors trading around the earnings announcement.

${ }^{17}$ For example, consider an earnings announcement observation where the firm's total trading volume over the prior 24 months is 400,000 shares. If only 100,000 shares were traded in the most recent 12 months, then the estimate of $\bar{\Delta} P$ for this observation receives a total weight of $1 / 4$ (or $100,000 / 400,000$ ). This assumes that $25 \%$ of investors trading at the earnings announcement date are potentially subject to an ITD at the earnings announcement. Conversely, if 300,000 of the 400,000 shares were traded in the most recent 12-month period, then the estimate of $\bar{\Delta} P$ for this observation receives a total weight of $3 / 4$, three times the weight of the other observation. Inferences do not change when cumulative three-year and five-year trading volume are used instead.

18 This definition is a direct result of constraining my sample to time periods with a one-year (or approximately 250 trading days) ITD requisite holding period. For example, investors who purchased shares 100 trading days before the earnings announcement date will have exactly 150 trading days remaining in their ITD requisite holding period (i.e., $250-100=150$ ).
} 
risk-free rate estimated over the 100 trading days immediately preceding day $t-1 .^{19}$

In addition, I also control for the influence of several factors that prior empirical research has found to be associated with trading volume around quarterly earnings announcements. The absolute value of unexpected earnings, $A U E$, is intended to control for the information made available at the earnings announcement (Bamber [1987]). AUE is equal to the absolute value of actual quarterly earnings per share announced on day $t$ minus the median analyst forecasts reported by $\mathrm{I} / \mathrm{B} / \mathrm{E} / \mathrm{S}$ over the 60 trading days prior to day $t-1$. In addition, I include the square of unexpected earnings, NONLINEAR, to capture any nonlinearities (e.g., Freeman and Tse [1992], Hurtt and Seida [2004]).

A number of factors related to the availability of preannouncement information and prior information disclosure are included as control variables. Firm size, SIZE, is the logarithm of market value of equity measured at the fiscal quarter-end preceding day $t$ and is a proxy for the level of prior information disclosure (Bamber [1986, 1987], Atiase and Bamber [1994]). NUM_EST is the logarithm of the number of analysts issuing a quarterly earnings forecast within 60 days prior to day $t-1$ and is a proxy for the rate of information flow (Hong, Lim, and Stein [2000]).

Finally, I include a proxy for the bid-ask spread at the earnings announcement date. The bid-ask spread represents another important transaction cost to investors that may influence their decisions to trade. Atkins and Dyl [1997] provide empirical evidence that annual trading volume is decreasing in the magnitude of the bid-ask spread. Following Atkins and Dyl [1997], I compute the average bid-ask spread, BID_ASK, for each observation as follows:

$$
B I D \_A S K=\frac{1}{10} \sum_{n=2}^{11} \frac{A S K_{j, t-n}-B I D_{j, t-n}}{\left(A S K_{j, t-n}+B I D_{j, t-n}\right) / 2},
$$

where $B I D_{j, t-n}$ and $A S K_{j, t-n}$ are the closing bid and ask prices for firm $j$ on day $t-n$.

\section{Empirical Analysis}

The purpose of this section is to test the empirical predictions from section 2. Section 4.1 presents univariate statistics for selected regression variables. In section 4.2, I empirically examine whether ITDs significantly influence the selling activity of individual investors around quarterly earnings announcement dates. Next, I present the fundamental empirical contributions of the paper by testing how risk influences the sensitivity of trading

\footnotetext{
${ }^{19}$ In section 4.4, I also consider a number of other proxies for the intensity component of risk, such as idiosyncratic and systematic return volatilities, as well as the skewness of the daily return distribution.
} 
T A B L E 1

Sample Distribution

\begin{tabular}{lrrrrrrr}
\hline \hline Variable & Mean & Std. Dev. & \multicolumn{1}{c}{ 1st } & 25th & Median & 75th & 99 th \\
\hline AVOL & 1.556 & 1.579 & -1.107 & -0.240 & 1.287 & 2.802 & 5.508 \\
$\triangle R A T E$ & 0.124 & 0.079 & 0.000 & 0.030 & 0.116 & 0.196 & 0.300 \\
$\bar{\Delta} P$ & 0.014 & 0.109 & -0.323 & -0.043 & 0.017 & 0.074 & 0.328 \\
$I T D$ & 0.002 & 0.017 & -0.056 & -0.003 & 0.000 & 0.008 & 0.053 \\
INTENSITY & 0.063 & 0.064 & 0.008 & 0.025 & 0.043 & 0.077 & 0.315 \\
UE & -0.091 & 0.977 & -4.800 & -0.171 & 0.000 & 0.124 & 3.401 \\
BID_ASK & 0.026 & 0.031 & 0.004 & 0.010 & 0.015 & 0.027 & 0.171 \\
SIZE & 4.681 & 15.628 & 0.055 & 0.380 & 1.013 & 3.059 & 68.801 \\
NUM_EST & 7.293 & 5.402 & 1.000 & 3.000 & 6.000 & 10.000 & 24.000 \\
\hline
\end{tabular}

The sample includes 35,222 observations of quarterly earnings announcements from 1982 to 2002. Let $t$ denote the quarterly earnings announcement date identified by Compustat. AVOL is the average of daily actual less daily expected selling activity by individual investors scaled by the standard deviation of selling activity, computed over days $t-1$ to $t+1$. Actual selling activity by individual investors is the natural logarithm of one plus the number of trades classified as sell orders by individual investors and the expectation and standard deviation of selling activity is the average and standard deviation, respectively, of the same selling metric over the 50 trading dates immediately preceding day $t-1$ (after excluding prior three-day earnings announcement windows). $\triangle R A T E$ is the maximum statutory short-term capital gains tax rate minus the maximum statutory long-term capital gains tax rate on day $t . \bar{\Delta} P$ is the volume-weighted, average price change over the prior 248 trading days immediately preceding day $t-2$ (within the requisite ITD holding period), $\frac{1}{248} \sum_{n=3}^{250} w_{n} \cdot \Delta P_{t-n}$, where $\Delta P_{t-n}$ is the logarithm of the stock price on day $t-2$ (adjusted for stock splits and stock dividends) minus the logarithm of the stock price on day $t-n$ and $w_{n}$ is equal to the daily volume on day $t-n$ divided by the firm's cumulative trading volume over the two years immediately preceding the earnings announcement. ITD is equal to the product of $\triangle R A T E$ and $\triangle P$. INTENSITY is 100 times the variance of daily changes in the logarithm of stock price estimated over the 100 trading days immediately preceding day $t-1$. UE is 100 the times the difference between announced quarterly earnings on day $t$ and the median analyst forecast within the 60 days preceding day $t-1$. BID_ASK is the average percentage bid-ask spread over the 10 trading days immediately preceding day $t-1$. SIZE is the market value of equity (in billions) at the end of the fiscal quarter preceding day $t$. NUM_EST is the number of analysts issuing a quarterly earnings forecast within 60 days prior to day $t-1$.

activity to ITDs by decomposing the risk of future adverse price changes into two components: the duration and the intensity of the risk. In section 4.3, I test whether duration (i.e., the length of time that a risk must be borne before an investor meets the ITD holding period requirement) affects trading around quarterly earnings announcements. Finally, in section 4.4, I investigate how the intensity of risk interacts with ITD incentives to influence trading.

\subsection{DESCRIPTIVE STATISTICS}

Table 1 presents the sample distribution of selected regression variables. Abnormal selling activity by individual investors around quarterly earnings announcements, AVOL, has a mean and standard deviation of 1.556 and 1.579 , respectively, which are comparable to values reported in prior ITD studies. The mean $\triangle R A T E$ is 0.116 and varies between 0.00 and 0.30 over the sample period. The mean (median) market value of equity is $\$ 4.681$ (\$1.013) billion and the mean (median) number of analysts following each firm is $7.3(6.0)$.

\subsection{ITDS AND TRADING ACTIVITY}

A necessary condition for risk to affect trading is that ITDs must have a significant influence on investors' trading decisions. As discussed 
earlier, Blouin, Raedy, and Shackelford [2003] and Hurtt and Seida [2004] document empirical evidence consistent with this necessary condition around quarterly earnings announcement dates, which provides preliminary support and serves as a benchmark for my tests. I test for this effect in my sample and find supporting evidence that corroborates the findings of prior studies. Testing the necessary condition is intended to provide a foundation, and serve as a point of departure, for examining the main empirical implications of my model: how the risk of adverse price change influences investors' trading decisions around quarterly earnings announcements given ITD incentives to postpone trade.

I employ the following OLS regression model to test for the necessary condition:

$$
A V O L=\beta_{0}+\beta_{1} \Delta R A T E+\beta_{2} \bar{\Delta} P+\beta_{3} I T D+\text { controls }+\epsilon,
$$

where a negative sign associated with $\beta_{3}$ is predicted if ITD transaction costs provide an incentive to investors to postpone trading. Table 2, column 1 presents the parameter estimates for this analysis, which is based on the entire sample. As expected, I find that $\beta_{3}$ is negative and statistically significant. ${ }^{20}$ This result complements similar evidence documented by Blouin, Raedy, and Shackelford [2003] and Hurtt and Seida [2004] and provides preliminary evidence that trading activity is decreasing in ITD transaction costs in my sample.

Is this result attributable to ITD effects? Investors are only taxed on realized trading profits (i.e., only if an asset has appreciated in value) but do not receive a direct ITD benefit (in the form of a tax subsidy) from the sale of assets that have depreciated. ${ }^{21}$ Therefore, investors' trading decisions when the asset has depreciated in value should be much less sensitive to ITD costs (i.e., the necessary condition may not be satisfied) compared to an asset that has appreciated in value and will generate an ITD tax. The asymmetric nature of tax incentives for appreciated versus depreciated assets provides a discriminating prediction capable of providing additional evidence attributable to an ITD effect. Specifically, I expect AVOL to exhibit a negative association with ITD when the aggregate price change over the prior holding period is greater than zero. Conversely, I expect to find no such relationship among stocks that have not appreciated over the holding period. Following Blouin, Raedy, and Shackelford [2003], I separate the sample into appreciated (i.e., $\bar{\Delta} P>0$ ) and depreciated (i.e., $\bar{\Delta} P \leq 0$ ) observations and estimate equation (3) for each sample. If the results in column 1 are attributable to ITD incentives to postpone trading, then I expect to find a negative sign on $\beta_{3}$ for the appreciated sample and a $\beta_{3}$ coefficient

\footnotetext{
${ }^{20}$ Standard errors for all specifications account for clustering by the month of the earnings announcement (see Petersen [2009]).

${ }^{21}$ As discussed earlier, investors may receive an indirect ITD benefit if they are able to offset a portion of a realized capital gain in an appreciated asset with a realized capital loss in another asset.
} 
T A B L E 2

Determinants of Selling Activity by Individual Investors Around Quarterly Earnings Announcements

\begin{tabular}{|c|c|c|c|c|c|c|c|}
\hline \multirow[b]{3}{*}{ Variable } & \multirow[b]{3}{*}{ Pred. } & \multicolumn{6}{|c|}{ Dependent Variable: $A V O L$} \\
\hline & & \multicolumn{2}{|c|}{$\begin{array}{c}\text { Full } \\
\text { Sample }\end{array}$} & \multicolumn{2}{|c|}{$\begin{array}{l}\text { Appreciated } \\
(\bar{\Delta} P>0)\end{array}$} & \multicolumn{2}{|c|}{$\begin{array}{c}\text { Depreciated } \\
(\bar{\Delta} P \leq 0)\end{array}$} \\
\hline & & Coeff. & $(t$-stat $)$ & Coeff. & ( $t$-stat) & Coeff. & $(t$-stat $)$ \\
\hline$\triangle R A T E$ & & -0.828 & $(-5.17)$ & 0.423 & $(2.00)$ & -0.926 & $(-5.07)$ \\
\hline $\bar{\Delta} P^{\mathrm{a}}$ & & 2.182 & $(6.94)$ & 2.396 & $(11.86)$ & 0.512 & $(1.15)$ \\
\hline$I T D^{\mathrm{a}}$ & $(-)$ & -4.414 & $(-3.60)$ & -5.709 & $(-3.35)$ & -0.655 & $(-0.75)$ \\
\hline$A U E^{\mathrm{b}}$ & & 0.238 & $(8.05)$ & 0.337 & $(10.10)$ & 0.148 & $(6.35)$ \\
\hline NONLINEAR $R^{\mathrm{b}}$ & & -0.027 & $(-3.65)$ & -0.039 & $(-4.36)$ & -0.015 & $(-5.52)$ \\
\hline$B I D \_A S K^{\mathrm{a}}$ & & -1.864 & $(-1.89)$ & -2.389 & $(-4.20)$ & 1.493 & (1.02) \\
\hline SIZE & & 0.112 & $(3.22)$ & 0.064 & $(4.29)$ & 0.164 & $(6.34)$ \\
\hline NUM_EST & & 0.019 & $(2.60)$ & 0.020 & $(2.50)$ & 0.016 & $(2.29)$ \\
\hline $\operatorname{Adj} . R^{2}$ & & \multicolumn{2}{|c|}{0.4058} & \multicolumn{2}{|c|}{0.4388} & \multicolumn{2}{|c|}{0.4303} \\
\hline Num. Obs. & & \multicolumn{2}{|c|}{35,222} & \multicolumn{2}{|c|}{22,360} & \multicolumn{2}{|c|}{12,862} \\
\hline
\end{tabular}

${ }^{\mathrm{a}}$ Variable winsorized at the $1 \%$ and $99 \%$ levels.

b Variable winsorized at the $99 \%$ level.

Let $t$ denote the quarterly earnings announcement date identified by Compustat. The dependent variable is the three-day abnormal selling activity by individual investors, AVOL, around quarterly earnings announcements from 1982 to 2002. Specifically, AVOL is the average of daily actual less daily expected selling activity by individual investors scaled by the standard deviation of selling activity, computed over days $t-1$ to $t+1$. Actual selling activity by individual investors is the natural logarithm of one plus the number of trades classified as sell orders by individual investors and the expectation and standard deviation of selling activity is the average and standard deviation, respectively, of the same selling metric over the 50 trading dates immediately preceding day $t-1$ (after excluding prior three-day earnings announcement windows). $\triangle R A T E$ is the maximum statutory short-term capital gains tax rate minus the maximum statutory long-term capital gains tax rate on day $t . \bar{\Delta} P$ is the volume-weighted, average price change over the prior 248 trading days immediately preceding day $t-2$ (within the requisite ITD holding period), $\frac{1}{248} \sum_{n=3}^{250} w_{n} \cdot \Delta P_{t-n}$, where $\Delta P_{t-n}$ is the logarithm of the stock price on day $t-2$ (adjusted for stock splits and stock dividends) minus the logarithm of the stock price on day $t-n$ and $w_{n}$ is equal to the daily volume on day $t-n$ divided by the firm's cumulative trading volume over the two years immediately preceding the earnings announcement. ITD is equal to the product of $\triangle R A T E$ and $\bar{\triangle} P$. AUE is 100 the times absolute value of the difference between announced quarterly earnings on day $t$ and the median analyst forecast within the 60 days preceding day $t-1$. NONLINEAR is equal to the square of AUE. BID_ASK is the average percentage bid-ask spread over the 10 trading days immediately preceding day $t-1$. SIZE is the logarithm of the market value of equity at the end of the fiscal quarter preceding day $t$. NUM_EST is the logarithm of the number of analysts issuing a quarterly earnings forecast within 60 days prior to day $t-1$. Firm fixed-effects are included and coefficient $t$-statistics are based on standard errors clustered by the month of the earnings announcement.

for the depreciated sample that is smaller in magnitude and not statistically different from zero. Table 2, columns 2 and 3 present results for the appreciated and depreciated samples, respectively. Consistent with a tax-related explanation, I find that $\beta_{3}$ for the appreciated sample is negative and significant (column 2), while $\beta_{3}$ for the depreciated sample is slightly negative but not statistically significant (column 3$).^{22}$

The empirical results of this section provide evidence that investors' trading decisions around quarterly earnings announcements are sensitive to

\footnotetext{
${ }^{22}$ At a given point in time, many investors will have already held their shares for longer than the requisite ITD holding period and, therefore, should not be sensitive to ITD transaction costs. In untabulated analyses, I include the stock price appreciation for days $t-249$ to $t-498$ and the interaction with $\triangle R A T E$. Both variables are not statistically different from zero in all specifications.
} 
ITD incentives to postpone trade. The results presented in table 2 provide evidence that the necessary condition of my model is satisfied and provides a foundation for testing the two main empirical implications of the model.

\subsection{THE IMPACT OF THE DURATION OF RISK ON ITDS AND TRADING ACTIVITY}

This section tests empirical implication 1, which states that as duration (i.e., the amount of time remaining in the requisite ITD holding period) increases, investors' trading decisions become less sensitive to ITD costs. This occurs because investors who do not trade now must bear the risk of adverse price changes until the end of the requisite holding period. As this length of time increases (i.e., the longer the investor must bear such risk), the more willing they are to incur the ITD cost by prematurely trading to avoid the higher risk of adverse price changes. I refer to this effect as the duration of risk.

The average ITD measure, used in the prior section, equally weights each day's price appreciation across all holding periods. Thus, the $\beta_{3}$ coefficient in (3) only measures the average ITD incentive among investors and is not capable of discriminating among the different risk-sharing incentives of investors with different amounts of time remaining until qualification.

To empirically test this prediction, I disaggregate the price change, $\bar{\Delta} P$, and $I T D$ variables in (3) into the 248 individual holding period components and include each as a separate explanatory variable. In other words, instead of one aggregate ITD variable, I now include 248 ITD variables, one for each day in the requisite holding period. This allows me to estimate a separate ITD coefficient for investors with different duration of risk incentives. For example, I include the price change, and corresponding ITD incentive, over the prior 248 days (day $t-250$ to $t-2$ ) as a separate explanatory variable that represents investors that have exactly one day remaining in their ITD requisite holding period. Within the same regression model, I also include the price change and ITD incentive of an investor that purchased shares five days prior to the earnings announcement and has 245 days remaining in their ITD requisite holding period. If investors consider the duration of risk when trading, then I expect the ITD incentive of the investor with one day remaining, $I T D_{1}$, to have a more negative coefficient than the ITD incentive of the investor with 245 days left, $I T D_{245}$. This follows as investors with a longer amount of time remaining in their ITD holding period are more willing to incur the higher ITD costs by prematurely trading in an effort to avoid having to face adverse price risk over a long duration of time.

To test the duration of risk effect, I estimate the following regression model:

$$
A V O L=\sum_{d=1}^{248} \beta_{\Delta P}(d) \cdot \Delta P_{d}+\sum_{d=1}^{248} \beta_{I T D}(d) \cdot I T D_{d}+\text { controls }+\epsilon,
$$


where $\quad \Delta P_{d}=\ln \left(P_{t-2}\right)-\ln \left(P_{t-(250-d)}\right) \equiv \ln \left(P_{t-2}\right)-\ln \left(P_{t-n}\right), \quad I T D_{d}=$ $\triangle R A T E \cdot \Delta P_{d}$. The estimated parameters, $\beta_{I T D}(d)$, in the model reflect the sensitivity of trading activity to the ITD transaction cost for an investor with a given duration, $d$, of risk. Based on the empirical predictions of section 2.3, $\beta_{I T D}(d)$ is expected to be an increasing function of the duration of risk, $d$ (i.e., $\beta_{I T D}(1)<\beta_{I T D}(2)<\cdots<\beta_{I T D}(247)<\beta_{I T D}(248)<0$ ). To test this prediction, I restrict each of the $248 \beta_{I T D}(d)$ estimates (and their main effects, $\left.\beta_{\Delta P}(d)\right)$ so they follow a linear function of duration, $d$. Specifically, the regression in (4) is estimated subject to the following coefficient restrictions:

$$
\begin{aligned}
& \beta_{\Delta P}(d)=\alpha_{0}+\alpha_{1} \cdot d, \\
& \beta_{I T D}(d)=\gamma_{0}+\gamma_{1} \cdot d,
\end{aligned}
$$

where $\alpha_{0}, \alpha_{1}, \gamma_{0}$ and $\gamma_{1}$ are estimated parameters that summarize the coefficient dynamics as a function of duration, $d .^{23,24}$ Specifically, $\gamma_{0}$ is an estimate of the sensitivity of trading activity to the ITD transaction cost for an investor with a very small duration of risk, which is expected to be negative. The parameter $\gamma_{1}$ is an estimate of the change in the sensitivity of trading activity to ITD transaction costs as the duration of risk, $d$, increases. It is expected to be positive, which is consistent with the investors placing less weight on ITD transaction costs (i.e., less negative association) as the duration of risk, $d$, that they must bear increases. ${ }^{25}$

\footnotetext{
${ }^{23}$ Placing restrictions on the dynamics of the individual coefficients is similar in spirit to traditional distributed lag models (e.g., Gonedes [1971], Falk and Miller [1977], Sougiannis [1994]) and mixed data sampling models (e.g., Ghysels, Santa-Clara, and Valkanov [2006], Ghysels, Sinko, and Valkanov [2007]).

${ }^{24}$ Estimating (4) subject to (6) and (7) is equivalent to estimating the following OLS regression: $A V O L=\alpha_{0} \cdot \sum_{d=1}^{248} \Delta P_{d}+\alpha_{1} \cdot \sum_{d=1}^{248} d \cdot \Delta P_{d}+\gamma_{0} \cdot \sum_{d=1}^{248} I T D_{d}+\gamma_{1} \cdot \sum_{d=1}^{248} d$. $I T D_{d}+$ controls $+\epsilon$.

${ }^{25}$ In addition to succinctly summarizing the dynamics of the coefficient estimates, the restrictions imposed by (6) and (7) reduce two other difficulties associated with a reasonable estimation of (7). First, adding the individual price changes and ITD incentives from the prior year requires the estimation of 496 additional coefficients, which significantly reduces the degrees of freedom. Second, many of the holding period price changes, $\Delta P_{d}$, are estimated across overlapping time periods, which introduces potential multicollinearity problems among the explanatory variables. For example, the price change of an investor with a duration of one day represents a cumulative 248-day price change. Similarly, within the same observation, an investor with a duration of two days has a 247-day price change. Both price changes share 247 daily price changes, which means they will be highly correlated. When severe multicollinearity exists, it becomes very difficult to precisely identify the separate effects among the explanatory variables. As a consequence, coefficient estimates will exhibit large sampling variances (see Judge et al. [1985]). This problem is further compounded by the inclusion of the remaining 246 price change variables, as well as 248 highly correlated $I T D_{d}$ variables. Restricting the individual coefficients to a small-dimension parameter space, as in (6) and (7), injects additional information into the regression through the parameterizing function, which imposes a large number of
} 
TA B L E 3

Regression Examining the Duration of Risk and Selling Activity by Individual Investors Around Quarterly Earnings Announcements

\begin{tabular}{|c|c|c|c|c|c|c|c|}
\hline \multicolumn{8}{|c|}{ Dependent Variable: $A V O L$} \\
\hline \multicolumn{2}{|c|}{ Parameters } & Pred. & Coeff. & $(t$-stat) & Parameters & Coeff. & $(t$-stat $)$ \\
\hline \multirow[t]{3}{*}{$I T D_{d}$} & $\gamma_{0}$ & $(-)$ & -12.895 & $(-4.19)$ & $\triangle R A T E$ & -0.815 & $(-4.97)$ \\
\hline & $\gamma_{1}$ & $(+)$ & 0.057 & $(3.07)$ & $A U E^{\mathrm{b}}$ & 0.231 & $(8.24)$ \\
\hline & & & & & NONLINEAR ${ }^{\mathrm{b}}$ & -0.027 & $(-3.17)$ \\
\hline \multirow[t]{3}{*}{$\Delta P_{d}$} & $\alpha_{0}$ & & -1.726 & $(-2.75)$ & BID_ASK $K^{\mathrm{a}}$ & -1.187 & $(-1.83)$ \\
\hline & $\alpha_{1}$ & & 0.040 & $(6.04)$ & SIZE & 0.118 & $(3.54)$ \\
\hline & & & & & NUM_EST & 0.018 & $(2.70)$ \\
\hline \multicolumn{8}{|c|}{ Adj. $R^{2}=0.4088$} \\
\hline \multicolumn{8}{|c|}{ Num. Obs. $=35,222$} \\
\hline
\end{tabular}

${ }^{\text {a }}$ Variable winsorized at the $1 \%$ and $99 \%$ levels.

${ }^{\mathrm{b}}$ Variable winsorized at the $99 \%$ level.

This table presents parameter estimates from the following regression model:

$$
\begin{gathered}
A V O L=\sum_{d=1}^{248} \beta_{\Delta P}(d) \cdot \Delta P_{d}+\sum_{d=1}^{248} \beta_{I T D}(d) \cdot I T D_{d}+\text { controls }+\varepsilon, \\
\text { subject to: } \quad \beta_{\triangle P}(d)=\alpha_{0}+\alpha_{1} \cdot d \\
\beta_{I T D}(d)=\gamma_{0}+\gamma_{1} \cdot d .
\end{gathered}
$$

Let $t$ denote the quarterly earnings announcement date identified by Compustat. The dependent variable is the three-day abnormal selling activity by individual investors, AVOL, around 35,222 quarterly earnings announcements from 1982 to 2002. Specifically, AVOL is the average of daily actual less daily expected selling activity by individual investors scaled by the standard deviation of selling activity, computed over days $t-1$ to $t+1$. Actual selling activity by individual investors is the natural logarithm of one plus the number of trades classified as sell orders by individual investors and the expectation and standard deviation of selling activity is the average and standard deviation, respectively, of the same selling metric over the 50 trading dates immediately preceding day $t-1$ (after excluding prior three-day earnings announcement windows). $\Delta P_{t-n}$ is equal to the logarithm of the stock price on day $t-2$ (adjusted for stock splits and stock dividends) minus the logarithm of the stock price on day $t-n$ scaled by 248 and weighted by the ratio of the firm's daily volume on day $t-n$ to the total trading volume over the two years immediately preceding the earnings announcement. $I T D_{d}$ is equal to the product of $\triangle R A T E$ and $\triangle P_{d}$, where $\triangle R A T E$ is the maximum statutory short-term capital gains tax rate minus the maximum statutory long-term capital gains tax rate on day $t$. Duration, $d$, is the number of trading days from the quarterly earnings announcement date, $t$, that an investor that purchased shares on day $t-n$ must hold the stock to meet the requisite ITD holding period of 250 trading days. Other controls (defined in section 3.2) include AUE, NONLINEAR, SIZE, and NUM_EST. Firm fixed-effects are included and coefficient $t$-statistics are based on standard errors clustered by the month of the earnings announcement.

Table 3 presents parameter estimates from (4) subject to (5) and (6). Consistent with my empirical predictions, I find that $\gamma_{0}$ is negative and statistically significant, and $\gamma_{1}$ is positive and statistically significant. This implies that the negative relationship between $A V O L$ and $I T D_{d}$ is increasing (i.e., becoming less negative) as the duration, $d$, of time investors must bear risk increases.

Specifically, the sensitivity of investors' trading decisions to ITD costs is increasing (i.e., becoming less negative) in duration. This is consistent with the notion that, all else being equal, when investors face more uncertainty

coefficient constraints. This reduces the sampling variability of coefficient estimates and counteracts increased variability from multicollinearity (see Judge et al. [1985], Kennedy [2003]). 
in the future (i.e., have a longer time to wait), postponing trade becomes more costly from a risk perspective, and thus the ITD incentive to postpone trading becomes relatively less important than the risk-related incentive to trade immediately.

The economic significance of the duration of risk on the sensitivity of trade to ITD costs is evident from the parameter estimates in table 3. For example, this sensitivity is highest (and statistically significant) for investors with the shortest duration of risk (i.e., $\beta_{I T D}(1)=\gamma_{0}+\gamma_{1}(1)=-12.838$ ), while the sensitivity of investors with the highest duration of risk is negligible (i.e., $\left.\beta_{I T D}(250)=\gamma_{0}+\gamma_{1}(250)=1.355\right)$ and not statistically different from zero. Thus, an increase in the duration of risk from 1 to 250 completely eliminates any ITD tax incentive to postpone trade because it imposes too high of an implicit cost on risk averse investors. Again, this result is consistent with the Hirshleifer Effect and highlights the important economic costs associated with anticipated information.

\subsection{THE IMPACT OF THE INTENSITY OF RISK ON ITDS AND TRADING ACTIVITY}

This section tests empirical implication 2, which states that, as the intensity of price fluctuations per unit of time increases, investors' trading decisions become less sensitive to ITD costs. Holding duration of risk and the ITD incentive to postpone trading constant, stocks with a higher expected daily return volatility pose a greater risk of adverse future price changes than do lower volatility stocks. I refer to this effect as the intensity of risk.

To test this prediction, I estimate the regression specified in (4) but alter the coefficient restrictions, (5) and (6), as follows:

$$
\begin{aligned}
& \beta_{\triangle P}(d)=\alpha_{0}+\alpha_{1} \cdot d+\alpha_{i n t} \cdot \text { INTENSITY, } \\
& \beta_{I T D}(d)=\gamma_{0}+\gamma_{1} \cdot d+\gamma_{i n t} \cdot \text { INTENSITY, }
\end{aligned}
$$

where a positive $\gamma_{i n t}$ is consistent with empirical implication 2 and INTENSITY is expressed as a sample rank. ${ }^{26}$

Table 4 presents the parameter estimates from (4), subject to (7) and (8). Consistent with my empirical predictions, I find that the coefficient $\gamma_{\text {int }}$ is positive and statistically significant, which signifies that the function describing $\beta_{I T D}(d)$ shifts upward as INTENSITY increases. This implies that investors' trading decisions become less sensitive to ITD costs as postponing trade becomes more costly from a risk perspective. Therefore, investors are more likely to pay the higher ITD cost to shed the risk of intense price

\footnotetext{
${ }^{26}$ In the conceptual framework outlined in section 2, trading volume is a function of the variance, and not of the standard deviation, of anticipated stock prices. However, this is an artifact of the stylized nature of the model's assumptions and there is no reason to believe that investors do not consider the standard deviation instead of the variance. In order to avoid any non-linear differences between the two measures, I use sample percentile ranks because both the standard deviation and variance will have exactly the same rank order. All other measures of INTENSITY I consider in the section are expressed as a sample percentile rank.
} 
TAB L E 4

Regression Examining the Intensity of Risk and Selling Activity by Individual Investors Around Quarterly Earnings Announcements

\begin{tabular}{|c|c|c|c|c|c|c|c|}
\hline \multicolumn{8}{|c|}{ Dependent Variable: $A V O L$} \\
\hline \multicolumn{2}{|c|}{ Parameters } & \multirow{2}{*}{$\frac{\text { Pred. }}{(-)}$} & \multirow{2}{*}{$\frac{\text { Coeff. }}{-11.048}$} & \multirow{2}{*}{$\frac{(t \text {-stat })}{(-2.55)}$} & \multirow{2}{*}{$\frac{\text { Parameters }}{\triangle R A T E}$} & \multirow{2}{*}{$\frac{\text { Coeff. }}{-0.987}$} & \multirow{2}{*}{$\frac{(t \text {-stat })}{(-5.46)}$} \\
\hline$\overline{I T D_{d}}$ & $\gamma_{0}$ & & & & & & \\
\hline & $\gamma_{1}$ & $(+)$ & 0.039 & $(4.14)$ & $A U E^{\mathrm{b}}$ & 0.246 & $(8.54)$ \\
\hline & $\gamma_{i n t}$ & $(+)$ & 2.848 & $(2.03)$ & NONLINEAR $R^{\mathrm{b}}$ & -0.028 & $(-3.38)$ \\
\hline & & & & & $B I D \_A S K^{\mathrm{a}}$ & -2.190 & $(-2.15)$ \\
\hline \multirow[t]{3}{*}{$\Delta P_{d}$} & $\alpha_{0}$ & & -1.971 & $(-3.03)$ & $S I Z E$ & 0.126 & $(3.85)$ \\
\hline & $\alpha_{1}$ & & 0.044 & $(6.50)$ & NUM_EST & 0.019 & $(2.85)$ \\
\hline & $\alpha_{i n t}$ & & -0.371 & $(-1.85)$ & INTENSITY & -0.328 & $(-3.32)$ \\
\hline \multicolumn{8}{|c|}{ Adj. $R^{2}=0.4120$} \\
\hline \multicolumn{8}{|c|}{ Num. Obs. $=35,222$} \\
\hline
\end{tabular}

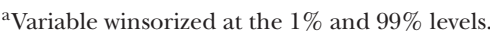

b Variable winsorized at the $99 \%$ level.

This table presents parameter estimates from the following regression:

$$
\begin{gathered}
A V O L=\sum_{d=1}^{248} \beta_{\Delta P}(\theta) \cdot \Delta P_{d}+\sum_{d=1}^{248} \beta_{I T D}(\theta) \cdot I T D_{d}+\text { controls }+\varepsilon, \\
\text { subject to: } \quad \beta_{\Delta P}(\theta)=\alpha_{0}+\alpha_{1} \cdot d+\alpha_{\text {int }} \cdot \text { INTENSITY, } \\
\beta_{I T D}(\theta)=\gamma_{0}+\gamma_{1} \cdot d+\gamma_{\text {int }} \cdot \text { INTENSITY, }
\end{gathered}
$$

where $\theta \in\{d, I N T E N S I T Y\}$. Let $t$ denote the quarterly earnings announcement date identified by Compustat. The dependent variable is the three-day abnormal selling activity by individual investors, $A V O L$, around 35,222 quarterly earnings announcements from 1982 to 2002. Specifically, AVOL is the average of daily actual less daily expected selling activity by individual investors scaled by the standard deviation of selling activity, computed over days $t-1$ to $t+1$. Actual selling activity by individual investors is the natural logarithm of one plus the number of trades classified as sell orders by individual investors and the expectation and standard deviation of selling activity is the average and standard deviation, respectively, of the same selling metric over the 50 trading dates immediately preceding day $t-1$ (after excluding prior three-day earnings announcement windows). $\Delta P_{t-n}$ is equal to the logarithm of the stock price on day $t-2$ (adjusted for stock splits and stock dividends) minus the logarithm of the stock price on day $t-n$ scaled by 248 and weighted by the ratio of the firm's daily volume on day $t-n$ to the total trading volume over the two years immediately preceding the earnings announcement. $I T D_{d}$ is equal to the product of $\triangle R A T E$ and $\triangle P_{d}$, where $\triangle R A T E$ is the maximum statutory short-term capital gains tax rate minus the maximum statutory long-term capital gains tax rate on day $t$. Duration, $d$, is the number of trading days from the quarterly earnings announcement date, $t$, that an investor, which purchased shares on day $t-n$, must hold the stock to meet the requisite ITD holding period of 250 trading days. INTENSITY is the variance of daily changes in the logarithm of stock price estimated over the 100 trading days immediately preceding day $t-1$ expressed as a fractional rank within the sample (high fractional rank corresponds to high variance). Other controls (defined in section 3.2) include AUE, NONLINEAR, SIZE, and NUM_EST. Firm fixed-effects are included and coefficient $t$-statistics are based on standard errors clustered by the month of the earnings announcement.

movements, holding duration constant. In addition, the coefficients $\gamma_{0}$ and $\gamma_{1}$ associated with duration are similar to the values reported in table 3 . All other control variables exhibit similar values to those reported in previous specifications.

This result highlights the important role of the intensity of risk on the sensitivity of trading to ITD costs. However, while the results are statistically significant, the economic magnitude is less pronounced compared to the duration of risk results discussed previously. For example, consider the sensitivity of an investor with the shortest duration (i.e., $d=1$ ) of risk. Moving from the lowest to highest intensity of risk 
(i.e, INTENSITY $=0$ to INTENSITY $=1$ ) reduces the magnitude of the sensitivity by $\gamma_{i n t}=2.848$, which reflects a decrease of approximately $25.7 \%$ relative to the benchmark sensitivity of $\gamma_{0}=-11.048$. This implies that for every $\$ 100$ risk-averse investors postpone trading in a stock with low intensity of risk in order to avoid paying any ITD taxes, they are willing to pay \$5.04 in additional taxes on immediate trade for a stock with high intensity of risk when the difference between the long-term and short-term tax rates, $\triangle R A T E$, is $19.6 \% .^{27}$ Thus, varying the intensity of risk from one extreme to the other does have a substantial economic impact on the sensitivity of trade to ITD costs, but reflects only one fourth of the economic impact of the duration of risk.

Recall from the analysis in section 4.2 that investors may have asymmetric ITD incentives depending on whether the price has appreciated or depreciated over the prior holding period. The specifications in tables 3 and 4 do not account for such differences in appreciated and depreciated prices and, therefore, in differences in ITD incentives to postpone trading. A potential solution is to partition the sample based on whether the stock has an average appreciation or an average depreciation over the prior holding period (see section 4.2 and results in table 2, columns 2 and 3). However, even if the average investor holding a stock has an appreciated basis, some investors holding the same stock will have a depreciated basis (as purchase prices vary over the prior holding period) and, therefore, different ITD incentives from an investor with an appreciated basis. Classifying observations based on the average amount of price appreciation destroys information about asymmetric ITD costs across different holding periods within the same observation. I allow appreciated holding periods to follow different functions describing $\beta_{\triangle P}(d)$ and $\beta_{I T D}(d)$ from those of depreciated holding periods. Specifically, (7) and (8) are adjusted as follows:

$$
\begin{aligned}
\beta_{\triangle P}(\theta)= & A P P_{d} \cdot\left(\alpha_{0}^{A}+\alpha_{1}^{A} \cdot d+\alpha_{i n t}^{A} \cdot \text { INTENSITY }\right) \\
& +D_{d} \cdot\left(\alpha_{0}^{D}+\alpha_{1}^{D} \cdot d+\alpha_{i n t}^{D} \cdot \text { INTENSITY }\right), \\
\beta_{I T D}(\theta)= & A P P_{d} \cdot\left(\gamma_{0}^{A}+\gamma_{1}^{A} \cdot d+\gamma_{i n t}^{A} \cdot \text { INTENSITY }\right) \\
& +{ }_{D E P} \cdot\left(\gamma_{0}^{D}+\gamma_{1}^{D} \cdot d+\gamma_{i n t}^{D} \cdot I N T E N S I T Y\right),
\end{aligned}
$$

where $\theta \in\left\{d, I N T E N S I T Y, A P P_{d}, D E P_{d}\right\} . A P P_{d}$ is an indicator variable equal to one if the change in stock price for an investor with duration $d$ is positive (i.e., $\Delta P_{d}>0$ ), and equal to zero otherwise. $D E P_{d}$ is an indicator variable equal to one if the change in stock price for an investor with duration $d$ is not positive (i.e., $\Delta P_{d} \leq 0$ ) and equal to zero otherwise. If investors have asymmetric ITD incentives with respect to appreciated and depreciated holding periods, then I expect the previous

\footnotetext{
${ }^{27}$ This value is computed as $\$ 100 \times 0.196 \times 0.257=\$ 5.04$
} 
TA B L E 5

Regression Examining the Intensity of Risk and Selling Activity by Individual Investors Around Quarterly Earnings Announcements for Appreciated and Depreciated Holding Periods

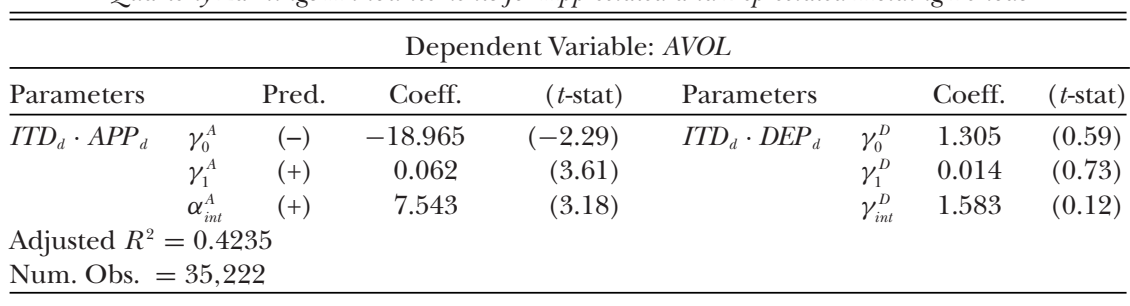

This table presents selected parameter estimates from the following regression:

$$
A V O L=\sum_{d=1}^{248} \beta_{\Delta P}(\theta) \cdot \Delta P_{d}+\sum_{d=1}^{248} \beta_{I T D}(\theta) \cdot I T D_{d}+\text { controls }+\varepsilon,
$$

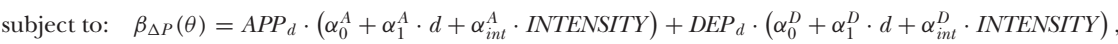
$\beta_{I T D}(\theta)=$ APP $_{d} \cdot\left(\gamma_{0}^{A}+\gamma_{1}^{A} \cdot d+\gamma_{i n t}^{A} \cdot \operatorname{INTENSITY}\right)+$ DEP $_{d} \cdot\left(\gamma_{0}^{D}+\gamma_{1}^{D} \cdot d+\gamma_{i n t}^{D} \cdot I N T E N S I T Y\right)$

where $\theta \in\left\{d, I N T E N S I T Y, A P P_{d}, D E P_{d}\right\}$. The dependent variable is the three-day abnormal selling activity by individual investors, AVOL (defined in section 3.2), around 35,222 quarterly earnings announcements from 1982 to 2002. $\Delta P_{t-n}$ is equal to the logarithm of the stock price on day $t-2$ (adjusted for stock splits and stock dividends) minus the logarithm of the stock price on day $t-n$ scaled by 248 and weighted by the ratio of the firm's daily volume on day $t-n$ to the total trading volume over the two years immediately preceding the earnings announcement. $I T D_{d}$ is equal to the product of $\triangle R A T E$ and $\triangle P_{d}$, where $\triangle R A T E$ is the maximum statutory short-term capital gains tax rate minus the maximum statutory long-term capital gains tax rate on day $t$. Duration, $d$, is the number of trading days from the quarterly earnings announcement date, $t$, that an investor that purchased shares on day $t-n$ must hold the stock to meet the requisite ITD holding period of 250 trading days. INTENSITY is the variance of daily changes in the logarithm of stock price estimated over the 100 trading days immediately preceding day $t-1$ expressed as a fractional rank within the sample (high fractional rank corresponds to high variance). $A P P_{d}$ is an indicator variable equal to one if the change in stock price for an investor with duration, $d$, is positive (i.e., $\Delta P_{d}>0$ ) and equal to zero otherwise. $D E P_{d}$ is an indicator variable equal to one if the change in stock price for an investor with duration, $d$, is not positive (i.e., $\Delta P_{d} \leq 0$ ) and equal to zero otherwise. Other controls (defined in section 3.2) include AUE, NONLINEAR, SIZE, and NUM_EST. Firm fixed-effects are included and coefficient $t$-statistics are based on standard errors clustered by the month of the earnings announcement.

results for $\beta_{I T D}(\theta)$ to reflect the influence of appreciated days (i.e., $\gamma_{\theta}^{A}$ coefficients are statistically significant with the predicted sign) rather than the influence of depreciated days (i.e., $\gamma_{\theta}^{D}$ coefficients are not statistically significant).

Table 5 presents the parameter estimates associated with $\beta_{I T D}(\theta)$ from (4), subject to (9) and (10). Consistent with an expected asymmetric ITD incentive between appreciated and depreciated price changes, I find that the coefficient estimates associated with appreciated holding periods (i.e., $\gamma_{\theta}^{A}$ ) have the predicted sign and are statistically significant. In particular, the coefficient $\gamma_{i n t}^{A}$ is positive and statistically significant with a higher magnitude than the value reported in table 4 . By contrast, the estimates associated with depreciated holding periods (i.e., $\gamma_{\theta}^{D}$ ) do not consistently have the predicted sign and are not statistically significant.

In addition to variance of the daily stock return distribution, I also consider three other proxies for the intensity component of risk: (1) the idiosyncratic variance of daily returns, (2) the systematic (market and twodigit industry) variance of daily returns, and (3) the coefficient of skewness 
of the daily return distribution. First, I examine whether the INTENSITY results in tables 4 and 5 are driven by idiosyncratic risk, systematic risk, or both by decomposing the total return variance, INTENSITY, into the idiosyncratic variance, IDIO, and the systematic variance, SYST. Specifically, $I D I O$ and SYST are equal to the variance of the residual and predicted values (expressed as a sample percentile rank), respectively, from a regression of firm-specific returns on the CRSP value-weighted market return and the two-digit industry return (e.g., see Roll [1988]) estimated over the 100 trading days immediately preceding day $t-1$, where $t$ is the quarterly earnings announcement date. Results for this specification are presented in table 6 , column 1. I find that $\gamma_{i d i o}^{A}$ is positive and statistically significant, while $\gamma_{\text {syst }}^{A}$ is positive but not statistically significant. These results indicate that, if investors attempt to hedge their risks (e.g., by short-selling similar assets), it may be difficult to find a substitute asset to hedge the idiosyncratic risk of adverse price changes while waiting for the ITD holding period to expire without triggering an immediate capital gain tax. Conversely, systematic risk does not significantly influence the sensitivity of investors' trading decisions to ITD costs.

Second, I examine the degree to which a firm's stock is "crash prone" by examining the degree of left-skewness in the daily return distribution. Specifically, I define $S K E W$ as the negative coefficient of skewness (expressed as a sample rank) of the firm-specific daily price change distribution, estimated over the 100 trading days immediately preceding day $t-1$. Following Chen, Hong, and Stein [2001], I compute SKEW as follows:

$$
S K E W=-\frac{100 \cdot 99^{3 / 2} \cdot \sum_{n=2}^{101} R_{t-n}^{3}}{99 \cdot 98 \cdot\left(\sum_{n=2}^{101} R_{t-n}^{2}\right)^{3 / 2}},
$$

where $R_{t-n}$ is the logarithm of the daily change in stock price on day $t-n$. Placing a minus sign on the coefficient of skewness adopts the convention that a higher value of $S K E W$ corresponds to a higher risk of a stock price "crash." Table 6, column 2 presents results for the specification in which INTENSITY is replaced with SKEW. Consistent with the INTENSITY results from table 5 , I find that $\gamma_{\text {skew }}^{A}$ is positive and statistically significant, which is consistent with a decrease in the sensitivity of investors' trading decisions to ITD costs as the probability of a large stock price "crash" (i.e., high SKEW) increases.

Finally, prior research documents a positive correlation between stock price volatility and the degree of institutional ownership in a firm (e.g., Potter [1992], Sias [1996]). Many institutions are exempt from paying capital gains taxes, leaving them with no ITD incentive to postpone trading. Because INTENSITY is based on the stock price volatility, it may simply serve as a proxy for the degree of institutional ownership and, therefore, capture the average tax status among traders at the quarterly earnings announcement date, rather than the risk of adverse price changes that 
TA B L E 6

Regression Examining Alternative Measures of Risk and Selling Activity by Individual Investors Around Quarterly Earnings Announcements

\begin{tabular}{|c|c|c|c|c|c|c|c|}
\hline \multirow[b]{3}{*}{ Parameters } & & \multicolumn{6}{|c|}{ Dependent Variable: $A V O L$} \\
\hline & & \multicolumn{2}{|c|}{ (1) } & \multicolumn{2}{|c|}{$(2)$} & \multicolumn{2}{|c|}{ (3) } \\
\hline & & Coeff. & $(t$-stat) & Coeff. & ( $t$-stat) & Coeff. & $(t$-stat $)$ \\
\hline \multirow[t]{6}{*}{$I T D_{d} \cdot A P P_{d}$} & $\gamma_{0}^{A}$ & -17.415 & $(-2.88)$ & -18.287 & $(-2.41)$ & -17.299 & $(-2.25)$ \\
\hline & $\gamma_{1}^{A}$ & 0.058 & $(3.71)$ & 0.057 & $(3.14)$ & 0.058 & (3.37) \\
\hline & $\gamma_{\text {idio }}^{A}$ & 8.365 & $(3.17)$ & & & 7.314 & $(3.08)$ \\
\hline & $\gamma_{s y s t}^{A}$ & 1.024 & $(0.27)$ & & & -0.271 & $(-0.89)$ \\
\hline & $\gamma_{\text {skew }}^{A}$ & & & 5.886 & $(3.64)$ & & \\
\hline & $\gamma_{\text {inst }}^{A}$ & & & & & -0.122 & $(-0.40)$ \\
\hline
\end{tabular}

This table presents selected parameter estimates from the following regression:

$$
A V O L=\sum_{d=1}^{248} \beta_{\Delta P}(\theta) \cdot \Delta P_{d}+\sum_{d=1}^{248} \beta_{I T D}(\theta) \cdot I T D_{d}+\text { controls }+\varepsilon,
$$

subject to: $\quad \beta_{\triangle P}(\theta)=A P P_{d} \cdot\left(\alpha_{0}^{A}+\alpha_{1}^{A} \cdot d+\alpha_{\text {idio }}^{A} \cdot I D I O+\alpha_{\text {syst }}^{A} \cdot S Y S T+\alpha_{\text {skew }}^{A} \cdot S K E W+\alpha_{\text {inst }}^{A} \cdot I N S T\right)$

$$
\begin{aligned}
& +D E P_{d} \cdot\left(\alpha_{0}^{D}+\alpha_{1}^{D} \cdot d+\alpha_{\text {idio }}^{D} \cdot I D I O+\alpha_{\text {syst }}^{D} \cdot S Y S T+\alpha_{\text {skew }}^{D} \cdot S K E W+\alpha_{\text {inst }}^{D} \cdot I N S T\right), \\
\beta_{I T D}(\theta)= & A P P_{d} \cdot\left(\gamma_{0}^{A}+\gamma_{1}^{A} \cdot d+\gamma_{\text {idio }}^{A} \cdot I D I O+\gamma_{\text {syst }}^{A} \cdot S Y S T+\gamma_{\text {skew }}^{A} \cdot S K E W+\gamma_{\text {inst }}^{A} \cdot I N S T\right) \\
& +D E P_{d} \cdot\left(\gamma_{0}^{D}+\gamma_{1}^{D} \cdot d+\gamma_{\text {idio }}^{D} \cdot I D I O+\gamma_{\text {syst }}^{D} \cdot S Y S T+\gamma_{\text {skew }}^{D} \cdot S K E W+\gamma_{\text {inst }}^{D} \cdot I N S T\right),
\end{aligned}
$$

where $\theta \in\left\{d, I D I O, S Y S T, S K E W, I N S T, A P P_{d}, D E P_{d}\right\}$. The dependent variable is the three-day abnormal selling activity by individual investors, $A V O L$ (defined in section 3.2), around 35,222 quarterly earnings announcements from 1982 to 2002. $\Delta P_{t-n}$ is equal to the logarithm of the stock price on day $t-2$ (adjusted for stock splits and stock dividends) minus the logarithm of the stock price on day $t-n$ scaled by 248 and weighted by the ratio of the firm's daily volume on day $t-n$ to the total trading volume over the two years immediately preceding the earnings announcement. $I T D_{d}$ is equal to the product of $\triangle R A T E$ and $\triangle P_{d}$, where $\triangle R A T E$ is the maximum statutory short-term capital gains tax rate minus the maximum statutory long-term capital gains tax rate on day $t$. Duration, $d$, is the number of trading days from the quarterly earnings announcement date, $t$, that an investor that purchased shares on day $t-n$ must hold the stock to meet the requisite ITD holding period of 250 trading days. INTENSITY is the variance of daily changes in the logarithm of stock price estimated over the 100 trading days immediately preceding day $t-1$ expressed as a fractional rank within the sample (high fractional rank corresponds to high variance). IDIO (SYST) is the residual (predicted) variance, expressed as a fractional rank, from a regression of firm-specific excess returns on the excess market return and the excess two-digit industry return estimated over the 100 trading days immediately preceding day $t-1$. SKEW, expressed as a fractional rank, is the negative coefficien of skewness of the firm-specific daily return distribution estimated over the 100 trading days immediately preceding day $t-1$. INST, expressed as a fractional rank, is the percentage of shares held by a 13-F filing institution at the end of the calendar quarter immediately preceding the earnings announcement date, $t$. $A P P_{d}$ is an indicator variable equal to one if the change in stock price for an investor with duration, $d$, is positive (i.e., $\Delta P_{d}>0$ ) and equal to zero otherwise. $D E P_{d}$ is an indicator variable equal to one if the change in stock price for an investor with duration, $d$, is not positive (i.e., $\Delta P_{d} \leq 0$ ) and equal to zero otherwise Other controls (defined in section 3.2) include AUE, NONLINEAR, SIZE, and NUM_EST. Firm fixed-effects are included and coefficient $t$-statistics are based on standard errors clustered by the month of the earnings announcement.

investors subject to an ITD may consider. I examine this possibility by computing the fraction of a firm's stock owned by institutional investors to test if it eliminates the statistical significance or changes the sign of $\gamma_{\text {idio }}^{A}$ in table 6 , column 1. Specifically, I include the percentage of shares held by 13-F filing institutions, INST (expressed as a sample rank), computed at the end of the calendar quarter immediately preceding the earnings announcement date. 
The results in table 6 , column 3 show that $\gamma_{i d i o}^{A}$ remains positive and statistically significant, while $\gamma_{\text {inst }}^{A}$ is negative and not statistically significant. The lack of significance associated with $\gamma_{i n s t}^{A}$ is consistent with the empirical evidence in Blouin, Raedy, and Shackelford [2003] illustrating that the degree of institutional ownership does not provide a discriminating ITD result for their sample. This indicates that INST may be a poor proxy for the true (unobservable) tax status of traders around an earnings announcement. Consequently, I cannot rule out the possibility that INTENSITY is simply a proxy for the fraction of investors that are subject to an ITD cost.

\subsection{THE IMPACT OF INVESTOR RISK AVERSION}

Investor risk aversion plays a critical role in the Hirshleifer Effect, which distinguishes it from alternative explanations for the observed relation among trading volume, ITD incentives, and the risk of future adverse price changes. In particular, Constantinides [1984] explicitly links stock return volatility to optimal trading decisions based on investors' option to realize losses short-term and gains long-term for tax purposes. In that study, the relation among trading volume, ITD incentives, and risk of future adverse price changes is unrelated to the Hirshleifer Effect because it does not rely on investor risk aversion. Thus, in this section I test whether the documented ITD/risk tradeoff varies as a function of investor risk aversion in order to distinguish it from the alternative timing option mechanism proposed by Constantinides [1984].

I compute an investor risk aversion index following Bollerslev, Gibson, and Zhou [2011]. This risk aversion index is calculated for each month between 1990 to 2002 and relies on sample moments of the model-free realized and option-implied (i.e., VIX) volatilities on the S\&P 500 index. In order to capture differential risk aversion that is orthogonal to investor's tax incentives, I first group observations based on their difference between the long-term and short-term tax rates $(\triangle R A T E)$. Within each $\triangle R A T E$ group, I then partition observations into above and below median (i.e., high and low) risk aversion index values. Finally, I separately estimate (4), subject to (9) and (10), for the high and low risk aversion subsamples.

Table 7 presents the parameter estimates associated with $\beta_{I T D}(\theta)$ for the high risk aversion subsample (column 1), the low risk aversion subsample (column 2) and the difference between them (column 3). I find that the coefficient estimates associated with appreciated holding periods have the predicted sign and are statistically significant for the high riskaversion subsample (column 1). In particular, the coefficient $\gamma_{i n t}^{A}$ is positive and statistically significant in the high risk aversion subsample and is higher in magnitude than the value reported for the low risk aversion subsample. The difference is statistically significant and indicates that an increase in risk aversion increases the effect of risk intensity on the sensitivity of investor's trading decision to ITD incentives, which is expected if the results are driven by the Hirshleifer Effect. Similarly, the coefficient $\gamma_{1}^{A}$, 
TA B L E 7

Regression Examining the Duration and Intensity of Risk and Selling Activity by Individual Investors Around Quarterly Earnings Announcements Partitioned into Time Periods of High and Low Investor Risk Aversion

\begin{tabular}{|c|c|c|c|c|c|c|c|}
\hline \multirow[b]{3}{*}{ Parameters } & & \multicolumn{4}{|c|}{ Investor Risk Aversion } & & \\
\hline & & \multicolumn{2}{|c|}{ High } & \multicolumn{2}{|c|}{ Low } & \multicolumn{2}{|c|}{ High - Low } \\
\hline & & Coeff. & $(t$-stat $)$ & Coeff. & $(t$-stat $)$ & Coeff. & $(t$-stat $)$ \\
\hline \multirow[t]{3}{*}{$I T D_{d} \cdot A P P_{d}$} & $\gamma_{0}^{A}$ & -24.035 & $(-3.78)$ & -8.106 & $(-2.61)$ & -15.929 & $(-2.03)$ \\
\hline & $\gamma_{1}^{A}$ & 0.115 & $(2.97)$ & 0.030 & $(0.88)$ & 0.085 & (2.01) \\
\hline & $\gamma_{\text {int }}^{A}$ & 9.677 & $(2.94)$ & 2.256 & $(0.57)$ & 7.421 & $(2.24)$ \\
\hline
\end{tabular}

This table presents selected parameter estimates from the following regression:

$$
A V O L=\sum_{d=1}^{248} \beta_{\Delta P}(\theta) \cdot \Delta P_{d}+\sum_{d=1}^{248} \beta_{I T D}(\theta) \cdot I T D_{d}+\text { controls }+\varepsilon,
$$

subject to: $\quad \beta_{\triangle P}(\theta)=A P P_{d} \cdot\left(\alpha_{0}^{A}+\alpha_{1}^{A} \cdot d+\alpha_{i n t}^{A} \cdot I N T E N S I T Y\right)+D E P_{d} \cdot\left(\alpha_{0}^{D}+\alpha_{1}^{D} \cdot d+\alpha_{i n t}^{D} \cdot I_{N T E N S I T Y}\right)$,

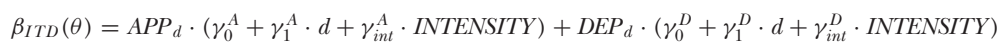

where $\theta \in\left\{d, I N T E N S I T Y, A P P_{d}, D E P_{d}\right\}$. The dependent variable is the three-day abnormal selling activity by individual investors, $A V O L$ (defined in section 3.2), around 24,557 quarterly earnings announcements from 1990 to 2002. $\Delta P_{t-n}$ is equal to the logarithm of the stock price on day $t-2$ (adjusted for stock splits and stock dividends) minus the logarithm of the stock price on day $t-n$ scaled by 248 and weighted by the ratio of the firm's daily volume on day $t-n$ to the total trading volume over the two years immediately preceding the earnings announcement. $I T D_{d}$ is equal to the product of $\triangle R A T E$ and $\triangle P_{d}$, where $\triangle R A T E$ is the maximum statutory short-term capital gains tax rate minus the maximum statutory long-term capital gains tax rate on day $t$. Duration, $d$, is the number of trading days from the quarterly earnings announcement date, $t$, that an investor that purchased shares on day $t-n$ must hold the stock to meet the requisite ITD holding period of 250 trading days. INTENSITY is the variance of daily changes in the logarithm of stock price estimated over the 100 trading days immediately preceding day $t-1$ expressed as a fractional rank within the sample (high fractional rank corresponds to high variance). $A P P_{d}$ is an indicator variable equal to one if the change in stock price for an investor with duration, $d$, is positive (i.e., $\Delta P_{d}>0$ ) and equal to zero otherwise. $D E P_{d}$ is an indicator variable equal to one if the change in stock price for an investor with duration, $d$, is not positive (i.e., $\left.\Delta P_{d} \leq 0\right)$ and equal to zero otherwise. Other controls (defined in section 3.2) include AUE, NONLINEAR, SIZE, and NUM_EST. Firm fixed-effects are included and coefficient $t$-statistics are based on standard errors clustered by the month of the earnings announcement. The first (second) column presents results for the subsample of observations with above (below) median investor risk aversion. The third column presents the difference between the first and second columns.

capturing the duration of risk, is positive and statistically significant in the high risk aversion subsample, which is higher in magnitude and statistically different from the value reported for the low risk aversion subsample and is consistent with the Hirshleifer Effect.

\section{Conclusions}

This paper theoretically and empirically investigates how the risk of future adverse price changes created by the anticipated arrival of information influences risk-averse investors' trading decisions in institutionally imperfect capital markets, which is commonly referred to as the Hirshleifer Effect (Hirshleifer [1971]). I examine the relation between trading activity and the risk of adverse price changes, as measured by stock price volatility, in the presence of trading frictions created by the existence of ITDs. An ITD refers to the incremental capital gains tax rate applied to trading profits on shares held for less than a requisite amount of time. Specifically, 
I examine how trading activity is influenced by the tradeoff between the risk-sharing benefits of immediate trade to mitigate exposure to future adverse price changes, and explicit transaction costs imposed upon such trades by the existence of an ITD.

Employing a stylized model, I demonstrate that current trading decisions depend upon two aspects of risk: the intensity of expected future price fluctuations per unit of time and the duration of time that risk must be borne. Tension in the model is created by introducing an incremental capital gains tax rate applied to trading profits on shares held for less than a requisite amount of time. Thus, risk-averse investors face an economic tension between trading immediately to an optimal risk-sharing portfolio at the cost of incurring an incremental tax on realized trading profits, versus postponing trade to avoid the incremental tax while facing the risk of interim, adverse price changes. Specifically, I find that the total amount of risk that each investor considers is an increasing function of both the intensity and the duration of the risk of adverse price changes. Intuitively, intensity captures the risk of adverse price movements per unit of time, while duration captures the amount of time that such risk must be held. The fact that investors can reduce tax costs by postponing the sale of shares until a known future point in time creates a unique opportunity to empirically test the Hirshleifer Effect.

I empirically examine whether the duration and intensity components of risk affect the sensitivity of abnormal trading activity by individual investors around quarterly earnings announcements to ITD transaction costs. Consistent with the model's predictions, I document evidence that, as the number of days left to avoid the incremental tax increases (i.e., duration of the risk increases), abnormal trading activity becomes less sensitive to the incremental transaction costs created by an ITD. Similarly, I find evidence that, as the expected volatility of future stock price increases (i.e., intensity of the risk increases), abnormal trading activity becomes less sensitive to ITD transaction costs. These results suggest that investors are more willing to incur explicit tax costs in order to insulate themselves against increases in the risk of price fluctuations driven by increases in the duration and intensity components of the risk. Overall, my analysis provides a novel and powerful setting in which to directly examine empirical implications of the adverse risk-sharing effect of anticipated information (i.e., the Hirshleifer Effect).

\section{APPENDIX}

\section{SHACKELFORD AND VERRECCHIA (2002)—EXTENSION}

The following analysis is a multiperiod extension of Shackelford and Verrecchia [2002], which employs a stylized model of pure exchange populated by risk-averse investors with homogenous risk preferences. Investors are endowed with shares of a risky asset and a risk-free bond in period 0 , trade shares of both in periods 1 and 2 , and consume wealth in 
period 3. One share of the bond (the numeraire commodity) pays one unit of consumption in period 3 , while the payoff from a share of the risky asset is a random variable, $\tilde{u}$. The per-capita supply of the risky asset, $x$, is common knowledge among investors and remains fixed across all time periods.

In period 0 , there are two distinct groups of investors, indexed by $i \in$ $\{B, S\} \equiv\{$ Buyers, Sellers $\}$, that differ only in their risk-free bond endowment, $E_{i}$, and risky asset endowment, $D_{0, i}$. Specifically, Buyers are endowed with a sufficiently "underweighted" amount of the risky asset (i.e., $D_{0, B}<x$ ) and therefore wish to buy additional shares. Conversely, Sellers are sufficiently "overweighted" (i.e., $D_{0, S}>x$ ) and therefore wish to sell a portion of their risky asset portfolio. ${ }^{28}$ In addition, each investor, $i$, is endowed with a basis, $P_{0}$, used to compute capital gains. Finally, let $\theta$ represent the relative proportion of Sellers in the economy, which is fixed across time. Therefore, in every period $t$, per-capita demand for the risky asset must equal per-capita supply: $\theta \cdot D_{t, S}+(1-\theta) \cdot D_{t, B}=x$. This identity implies that the aggregate change in demand across any number of time periods, $r$, is equal to zero:

$$
\theta\left(D_{t+r, S}-D_{t, S}\right)+(1-\theta)\left(D_{t+r, B}-D_{t, B}\right)=0,
$$

where $D_{t, i}$ is investor $i$ 's demand for the risky asset in period $t$.

In period 1, investors' expectations about $\tilde{u}$ are that it has a normal distribution with a mean of $\bar{u}$ and, without loss of generality, a variance equal to one. Given these common beliefs, investors trade shares of the risky asset and risk-free bond at competitive prices.

Investors' period 1 demand functions are driven by two opposing economic forces. First, following Shackelford and Verrecchia [2002], I assume periods 0 and 1 are sufficiently close in time so that any trading profits from the sale of assets in period 1 are taxed at an unfavorable short-term capital gains tax rate, $\tau$. Investors can reduce their taxes by postponing their trading activity until period 2, when a second round of trade opens. Period 2 is sufficiently distant in time from period 1 so that any realized trading profits in this period qualify for a favorable long-term capital gains tax, which is normalized to zero. Therefore, $\tau$ represents the spread between the shortterm and long-term capital gains tax rates and captures the incremental incentive created by an ITD to postpone trading until period 2.

\footnotetext{
${ }^{28}$ The assumption that investors hold less than an optimal risk-sharing amount is made to generate trading volume that triggers capital gains taxes. In this model, there are two situations in which no trade results. First, investors will not trade if they are endowed with an optimal risksharing amount of the risky asset, $x$ (Milgrom and Stokey [1982]). Second, even if investors are given suboptimal risk-sharing endowments, they may not trade if their initial allocations are sufficiently close to optimal risk-sharing such that the marginal ITD cost is higher than the marginal risk-sharing benefit of trading the first share. I avoid this uninteresting scenario by assuming that investors are "sufficiently" overweighted and underweighted in the risky asset. Therefore, my model is intended to shed light on how anticipated information incrementally influences trading volume, given a desire to trade, and is not intended to explain why trading volume exists.
} 
Second, investors anticipate they will observe a public signal, $\tilde{y}=\tilde{u}+\tilde{\varepsilon}$, between periods 1 and 2 . The noise in the signal, $\tilde{\varepsilon}$, is independently and normally distributed with a mean of 0 and a precision (inverse of variance) of $s$. The information contained in this signal creates an incentive for riskaverse investors to trade in period 1 to protect themselves from adverse price changes in period 2.

The model concludes in period 3 when investors realize the payoff of the risky asset, pay any capital gains taxes, and consume their remaining wealth. Investors are risk-averse with a utility for wealth characterized by a negative exponential utility function, $U\left(\tilde{W}_{i}\right)=-\exp \left(-\tilde{W}_{i} / \gamma\right)$, where $\gamma$ is a risk tolerance parameter common to all investors. $\tilde{W}_{i}$ is investor $i$ 's final wealth, which is equal to:

$$
\begin{aligned}
\tilde{W}_{i}= & E_{i}+P_{1}\left(D_{0, i}-D_{1, i}\right)+P_{2}\left(D_{1, i}-D_{2, i}\right)+\tilde{u} \cdot D_{2, i} \\
& -\tau_{i}\left(P_{1}-P_{0}\right)\left(D_{0, i}-D_{1, i}\right),
\end{aligned}
$$

where $P_{1}$ and $P_{2}$ are the prices of the risky asset and $D_{1, i}$ and $D_{2, i}$ are investor $i$ 's demand for the risky asset in periods 1 and 2 , respectively. The final term in equation (A.2) reflects the total amount of capital gains taxes paid by investor $i$ on realized trading profits in period 1 .

The equilibrium price and demand functions in period 1 are solved using backward induction. In period 2, trader $i$ maximizes his expected utility with respect to his demand for the risky asset, $D_{2, i}$, conditional upon observing the intermediate public signal, $\tilde{y}$. Because investor $i$ 's period 1 tax rate, $\tau_{i}$, does not affect this optimization problem, it is straightforward to solve for the equilibrium in period 2 :

$$
\begin{aligned}
\tilde{P}_{2} & =\frac{\bar{u}+s \tilde{y}}{1+s}-\frac{x}{\gamma(1+s)}, \\
D_{2, i} & =x, \quad \forall i .
\end{aligned}
$$

Equations (A.3) and (A.4) are standard for a model of this type in which all information is public and investors have homogenous risk preferences (e.g., Verrecchia [1982]). Each investor, regardless of type, holds a share of the risky asset equal to the per-capita supply, $x .^{29}$

In period 1 , investor $i$ 's optimization problem is to maximize expected utility, $\bar{U}_{i}$, given the period 2 equilibrium price and demand functions:

$$
\underset{D_{1, i}}{\operatorname{Max}} \bar{U}_{i}=E_{\tilde{u}, \tilde{P}_{2}}\left[-\exp \left(-\tilde{W}_{i} / \gamma\right)\right]
$$

Substituting the relation $D_{2, i}=x$ (from equation A.4) and using the moment-generating function for the normal random variables $\tilde{P}_{2}$ and $\tilde{u}$,

\footnotetext{
${ }^{29}$ In the presence of an ITD, investors in this two-period model do eventually achieve an optimal risk-sharing portfolio prior to the realization of the risky asset payoff. In contrast, investors in the one-period ITD model of Shackelford and Verrecchia [2002] never reach such an optimal risk-sharing portfolio.
} 
investor $i$ 's problem becomes:

$$
\begin{aligned}
& \operatorname{Max}_{D_{1, i}} \bar{U}_{i}=-\exp \left\{-\frac{1}{\gamma}\left[E_{i}+\left(P_{1}\left(1-\tau_{i}\right)+P_{0} \tau_{i}\right) \cdot D_{0, i}+\left(E\left[\tilde{P}_{2}\right]\right.\right.\right. \\
& \left.\left.\left.\quad-P_{1}\left(1-\tau_{i}\right)-P_{0} \tau_{i}\right) \cdot D_{1, i}+\left(\bar{u}-E\left[\tilde{P}_{2}\right]\right) \cdot x\right]+\frac{1}{2 \gamma^{2}}\left(D_{1, i}^{2}-x^{2}\right) \operatorname{Var}\left[\tilde{P}_{2}\right]\right\} .
\end{aligned}
$$

Differentiating this expression with respect to $D_{1, i}$, setting it equal to zero, and solving for $D_{1, i}$ yields:

$$
D_{1, i}=\frac{E\left[\tilde{P}_{2}\right]-P_{1}\left(1-\tau_{i}\right)-P_{0} \tau_{i}}{\frac{1}{\gamma} \operatorname{Var}\left[\tilde{P}_{2}\right]} .
$$

In period 1, Sellers will incur a tax, $\tau_{S}=\tau$, on any trading profits. Conversely, Buyers will not pay taxes, $\tau_{B}=0$, on any shares they purchase in period 1. Consequently, the demand functions of Buyers and Sellers can be expressed, respectively, as

$$
\begin{gathered}
D_{1, B}=\frac{E\left[\tilde{P}_{2}\right]-P_{1}}{\frac{1}{\gamma} \operatorname{Var}\left[\tilde{P}_{2}\right]}, \\
D_{1, S}=\frac{E\left[\tilde{P}_{2}\right]-P_{1}(1-\tau)-\tau P_{0}}{\frac{1}{\gamma} \operatorname{Var}\left[\tilde{P}_{2}\right]} .
\end{gathered}
$$

Applying the market clearing condition and substituting (A.7) and (A.8) yields:

$$
x=\theta D_{1, S}+(1-\theta) D_{1, B}=\frac{E\left[\tilde{P}_{2}\right]-P_{1}(1-\theta \tau)-\theta \tau P_{0}}{\frac{1}{\gamma} \operatorname{Var}\left[\tilde{P}_{2}\right]} .
$$

The unconditional expectation and variance of $\tilde{P}_{2}$ (from equation A.3) are given, respectively, by:

$$
\begin{gathered}
E\left[\tilde{P}_{2}\right]=\bar{u}-\frac{x}{\gamma(1+s)}, \\
\operatorname{Var}\left[\tilde{P}_{2}\right]=\frac{s}{(1+s)} .
\end{gathered}
$$

Substituting (A.10) and (A.11) into (A.9) and solving for $P_{1}$ yields:

$$
P_{1}=\frac{\bar{u}-\frac{x}{\gamma}-\theta \tau P_{0}}{1-\theta \tau} .
$$

Similarly, substituting (A.10) and (A.11) into (A.7) and (A.8) and simplifying each expression gives:

$$
D_{1, S}=x+\frac{\gamma\left(1+\frac{1}{s}\right) \tau(1-\theta)\left(\bar{u}-\frac{x}{\gamma}-P_{0}\right)}{(1-\theta \tau)},
$$




$$
D_{1, B}=x-\frac{\gamma\left(1+\frac{1}{s}\right) \theta \tau\left(\bar{u}-\frac{x}{\gamma}-P_{0}\right)}{(1-\theta \tau)} .
$$

By definition, the per-capita trading volume in period 1 is equal to

$$
\begin{aligned}
V_{1} & =\frac{1}{2} \int\left|D_{1, i}-D_{0, i}\right| d i \\
& =\frac{1}{2} \theta\left|D_{1, S}-D_{0, S}\right|+\frac{1}{2}(1-\theta)\left|D_{1, B}-D_{0, B}\right| \\
& =\frac{1}{2}\left[\theta\left(D_{0, S}-D_{1, S}\right)+(1-\theta)\left(D_{1, B}-D_{0, B}\right)\right],
\end{aligned}
$$

where the last step follows because Buyers (Sellers) do not sell (buy) shares in period 1. Substituting (A.1) into (A.12), per-capita trading volume is expressed in terms of Buyers demand:

$$
V_{1}=(1-\theta)\left(D_{1, B}-D_{0, B}\right)
$$

Finally, substituting the (A.10) into (A.13) leads to the following expression for trading volume in period 1 :

$$
\begin{aligned}
& \text { ITD incentive to } \\
& \text { postpone trade } \\
& V_{1}=V^{*}-\gamma \theta(1-\theta) \frac{\overbrace{\tau \Delta P_{1}}^{\operatorname{Var}\left[\tilde{P}_{2}\right]}}{\underbrace{\operatorname{Pachtve}}}, \\
& \text { risk incentive to } \\
& \text { trade immediately }
\end{aligned}
$$

where $V^{*}=(1-\theta)\left(x-D_{0, B}\right)$ is the optimal risk-sharing trading volume in period 1 and $\Delta P_{1}=P_{1}-P_{0}$ is the capital gain in period 1 .

\section{EXPECTED UTILITY AND THE HIRSHLEIFER EFFECT}

Substituting the equilibrium relations from (A.6) and (A.11) into (A.5) and rearranging terms, gives investor $i$ 's expected utility:

$$
\begin{aligned}
\bar{U}_{i}= & -\exp \left\{-\frac{1}{\gamma}\left[E_{i}+\left(P_{1}\left(1-\tau_{i}\right)+P_{0} \tau_{i}\right) \cdot D_{0, i}\right]\right. \\
& \left.-\frac{1}{2 \gamma^{2}}\left(D_{1, i}^{2}+x^{2}\right) \operatorname{Var}\left[\tilde{P}_{2}\right]-\frac{x^{2}}{\gamma(1+s)}\right\} .
\end{aligned}
$$


Differentiating (A.14) with respect to $s$ gives:

$$
\begin{aligned}
& \frac{\partial \bar{U}_{i}}{\partial s}=-\exp \{\bullet\} \cdot[-\frac{\operatorname{Var}\left[\tilde{P}_{2}\right] \cdot D_{1, i}}{\gamma^{2}} \cdot \frac{\partial D_{1, i}}{\partial s}-\frac{\left(D_{1, i}^{2}+x^{2}\right)}{2 \gamma^{2}} \\
&\left.\times \frac{\partial \operatorname{Var}\left[\tilde{P}_{2}\right]}{\partial s}+\frac{x^{2}}{\gamma^{2}(1+s)^{2}}\right] \\
&=-\exp \{\bullet\} \cdot[-\frac{\operatorname{Var}\left[\tilde{P}_{2}\right] \cdot D_{1, i}}{\gamma^{2}} \cdot \frac{\left(x-D_{1, i}\right)}{(1+s)^{2} \operatorname{Var}\left[\tilde{P}_{2}\right]}-\frac{\left(D_{1, i}^{2}+x^{2}\right)}{2 \gamma^{2}} \\
&\left.\times \frac{1}{(1+s)^{2}}+\frac{x^{2}}{\gamma^{2}(1+s)^{2}}\right] \\
&=-\frac{\exp \{\bullet\}}{2 \gamma^{2}(1+s)^{2}} \cdot\left(D_{1, i}-x\right)^{2} \leq 0 .
\end{aligned}
$$

If $\tau=0$, then $D_{1, i}=x$, which gives $\left.\frac{\partial \bar{U}_{i}}{\partial s}\right|_{\tau=0}=0$ from the above expression.

If $\tau>0$, then $D_{1, i} \neq x$, which gives $\left.\frac{\partial \bar{U}_{i}}{\partial s}\right|_{\tau>0}<0$. Together, this implies that $\frac{\partial}{\partial \tau}\left(\frac{\partial \bar{U}_{i}}{\partial s}\right)<0$.

\section{REFERENCES}

AJINKYA, B. B., AND P. C. JAIN. "The Behavior of Daily Stock Market Trading Volume." Journal of Accounting and Economics 11 (1989): 331-59.

Alles, M., AND R. Lundholm. "On the Optimality of Public Signals in the Presence of Private Information.” Accounting Review 68 (1993): 93-112.

Atiase, R. K., AND L. S. BAMBER. "Trading Volume Reactions to Annual Accounting Earnings Announcements." Journal of Accounting and Economics 17 (1994): 309-29.

Atkins, A. B., AND E. A. Dyl. "Transaction Costs and Holding Periods for Common Stocks." Journal of Finance 52 (1997): 309-25.

BAmber, L. S. "The Information Content of Annual Earnings Releases: A Trading Volume Approach." Journal of Accounting Research 24 (1986): 40-56.

BAMBER, L. S. "Unexpected Earnings, Firm Size, and Trading Volume Around Quarterly Earnings Announcements." Accounting Review 62 (1987): 510-32.

BEAVER, W. H. "The Information Content of Annual Earnings Announcements." Journal of Accounting Research 6 (1968): 67-92.

Blouin, J. L.; J. S. RAEDY; AND D. A. SHACKELFORD. "Capital Gains Taxes and Equity Trading: Empirical Evidence.” Journal of Accounting Research 41 (2003): 611-51.

Bollerslev, T.; M. GiBSON; AND H. ZHOU. "Dynamic Estimation of Volatility Risk Premia and Investor Risk Aversion from Option Implied and Realized Volatilities." Journal of Econometrics 160 (2011): 235-45.

Bushman, R. M. "Public Disclosure and the Structure of Private Information Markets.," Journal of Accounting Research 29 (1991): 261-76.

CAmpBell, C. M. "Blackwell's Ordering and Public Information." Journal of Economic Theory 114 (2004): 179-97.

Chen, J.; H. HonG; AND J. C. STEIN. "Forecasting Crashes: Trading Volume, Past Returns, and Conditional Skewness in Stock Prices.” Journal of Financial Economics 61 (2001): 345-81.

Constantinides, G. M. "Optimal Stock Trading with Personal Taxes: Implications for Prices and Abnormal January Returns." Journal of Financial Economics 13 (1984): 65-89.

COnstantinides, G. M. "Capital Market Equilibrium with Transaction Costs." Journal of Political Economy 94 (1986): 842-62. 
DAI, Z.; E. L. MAYDEw; D. A. ShaCkelford; AND H. H. Zhang. "Capital Gains Taxes and Asset Prices: Capitalization or Lock In?” Journal of Finance 63 (2008): 709-42.

Diamond, D., AND R. E. Verrecchia. "Constraints on Short-Selling and Asset Price Adjustment to Private Information.” Journal of Financial Economics 18 (1987): 277-311.

DiAmOND, D. W. "Optimal Release of Information by Firms." Journal of Finance 40 (1985): 1071-94.

FALK, H., AND J. C. MILLER. "Amortization of Advertising Expenditures." Journal of Accounting Research 15 (1977): 12-22.

FAMA, E. "Efficient Capital Markets: A Review of Theory and Empirical Work." Journal of Finance 35 (1970): 383-417.

FAMA, E. "Efficient Capital Markets II." Journal of Finance 46 (1991): 1575-1617.

FOSTER, N. The FASB and the Capital Markets. The FASB Report. Norwalk, CT: FASB, 2003.

Freeman, R. N., AND S. Y. TSE. "A Nonlinear Model of Security Price Responses to Unexpected Earnings.” Journal of Accounting Research 30 (1992): 185-209.

GAO, P. "Disclosure Quality, Cost of Capital, and Investor Welfare." The Accounting Review 85 (2010): 1-29.

GHYSels, E.; P. SANTA-ClaRA; AND R. VALKanOV. "Predicting Volatility: Getting the Most Out of Return Data Sampled at Different Frequencies." Journal of Econometrics 131 (2006): 59-95.

GHYSEls, E.; A. SINKO; AND R. VALKANOV. "MIDAS Regressions: Further Results and New Directions." Econometric Reviews 26 (2007): 53-90.

Gonedes, N. J. "Some Evidence on Investor Actions and Accounting Messages-Part II." Accounting Review 46 (1971): 535-51.

Hakansson, N. H.; G. Kunkel; AND J. A. OHLSON. "Sufficient and Necessary Conditions for Information to Have Social Value in Pure Exchange." Journal of Finance 37 (1982): 1169-81.

Hirshleifer, J. "The Private and Social Value of Information and the Reward to Inventive Activity." American Economic Review 61 (1971): 561-74.

Hong, H.; T. Lim; AND J. C. Stein. "Bad News Travels Slowly: Size, Analyst Coverage, and the Profitability of Momentum Strategies.” Journal of Finance 60 (2000): 265-95.

HurtT, D. N., AND J. A. SEIDA. "Do Holding Period Tax Incentives Affect Earnings Release Period Selling Activity of Individual Investors?" Journal of the American Taxation Association 26 (2004): 43-64.

JIN, L. "Capital Gains Tax Overhang and Price Pressure." Journal of Finance 61 (2006): 1399-1431.

Judge, G. G.; W. E. Griffiths; R. C. Hill; H. LÜTKePhohl; And T.-C. LeE. The Theory and Practice of Econometrics. New York: John Wiley and Sons, 1985.

KENNEDY, P. A Guide to Econometrics. Cambridge, MA: MIT Press, 2003.

KLEIN, P. "The Capital Gain Lock-in Effect and Equilibrium Returns." Journal of Public Economics 71 (1999): 355-78.

LANDSMAN, W. R., AND E. L. MAYDEW. "Has the Information Content of Quarterly Earnings Announcements Declined in the Past Three Decades?" Journal of Accounting Research 40 (2002): $797-808$.

LANDSman, W. R., AND D. A. SHAckelford. "The Lock-in Effect of Capital Gains Taxes: Evidence from the RJR Nabisco Leveraged Buyout.” National Tax Journal 48 (1995): 245-59.

LEE, C. M. C., AND B. RADHAKRISHNA. "Inferring Investor Behavior: Evidence from TORQ Data." Journal of Financial Markets 3 (2000): 83-111.

LEE, C. M. C., AND M. J. READY. "Inferring Trade Direction from Intraday Data." Journal of Finance 46 (1991): 733-46.

Lerman, C.; S. Narod; K. Schulman; C. Hughes; A. Gomez-Caminero; G. Booney; K. Gold; B. Trock; D. Main; J. Lynch; C. Fulmore; C. SnYder; S. J. Lemon; T. Conway; P. Tonin; G. LENOIR; AND H. LYNCH. "BRCA1 Testing in Families with Hereditary Breast-Ovarian Cancer." Journal of the American Medical Association 275 (1996): 1885-92.

Lintner, J. "The Valuation of Risk Assets and the Selection of Risky Investment in Stock Portfolios and Capital Budgets." Review of Economics and Statistics 47 (1965): 13-37.

Marshall, J. "Private Incentives and Public Information." American Economic Review 64 (1974): 373-90. 
Merton, R. C. "A Simple Model of Capital Market Equilibrium with Incomplete Information." Journal of Finance 42 (1987): 483-510.

Milgrom, P., AND N. STOKEy. "Information, Trade and Common Knowledge." Journal of Economic Theory 26 (1982): 17-27.

Morse, D. "Prices and Trading Volume Reaction Surrounding Earnings Announcements: A Closer Examination.” Journal of Accounting Research 19 (1981): 374-83.

Petersen, M. A. "Estimating Standard Errors in Finance Panel Data Sets: Comparing Approaches." Review of Financial Studies 22 (2009): 435-80.

PotTER, G. "Accounting Earnings Annoucements, Institutional Investor Concentration, and Common Stock Returns.” Journal of Accounting Research 30 (1992): 146-55.

QUAID, K. A., AND M. MORRIS. "Reluctance to Undergo Predictive Testing: The Case of Huntington Disease." American Journal of Medical Genetics 45 (1993): 41-45.

ReESE, W. A. "Capital Gains Taxation and Stock Market Activity: Evidence from IPOs." Journal of Finance 53 (1998): 1799-1819.

RoLL, R. "R²." Journal of Finance 43 (1988): 541-66.

SHACKELFORD, D. A., AND T. SHEvlin. "Empirical Tax Research in Accounting." Journal of Accounting and Economics 31 (2001): 321-87.

SHACKElford, D. A., AND R. E. VERRECCHIA. "Intertemporal Tax Discontinuities." Journal of Accounting Research 40 (2002): 205-22.

SHARPE, W. "Capital Asset Prices: A Theory of Market Equilibrium Under Conditions of Risk." Journal of Finance 19 (1964): 425-42.

SIAS, R. W. "Volatility and the Institutional Investor." Financial Analysts Journal 52 (1996): $13-20$.

SougIANNIS, T. "Accounting Based Valuation of Corporate R\&D." Accounting Review 69 (1994): 44-68.

VerrecchiA, R. E. "The Use of Mathematical Models in Financial Accounting." Journal of Accounting Research 20 (1982): 1-42.

VerrecchiA, R. E. "Essays on Disclosure." Journal of Accounting and Economics 32 (2001): 97-180. 